\title{
Two-Phase Alkali-Metal Experiments in Reduced Gravity
}

\author{
Z. I. Antoniak
}

June 1986

Prepared for the U.S. Department of Energy under Contract DE-AC06-76RLO 1830

Pacific Northwest Laboratory Operated for the U.S. Department of Energy by Battelle Memorial Institute 


\title{
DISCLAIMER
}

This report was prepared as an account of work sponsored by an agency of the United States Government. Neither the United States Government nor any agency thereof, nor any of their employees, makes any warranty, express or implied, or assumes any legal liability or responsibility for the accuracy, completeness, or usefulness of any information, apparatus, product, or process disclosed, or represents that its use would not infringe privately owned rights. Reference herein to any specific commercial product, process, or service by trade name, trademark, manufacturer, or otherwise, does not necessarily constitute or imply its endorsement, recommendation, or favoring by the United States Government or any agency thereof. The views and opinions of authors expressed herein do not necessarily state or reflect those of the United States Government or any agency thereof.

\author{
PACIFIC NORTHWEST LABORATORY \\ operated by \\ BATTELLE \\ for the \\ UNITED STATES DEPARTMENT OF ENERGY \\ under Contract DE-AC06-76RLO 1830
}

\begin{tabular}{|c|c|}
\hline \multicolumn{2}{|c|}{ Printed in the United States of America } \\
\hline \multicolumn{2}{|c|}{ Available from } \\
\hline \multirow{4}{*}{\multicolumn{2}{|c|}{$\begin{array}{c}\text { National Technical Information Service } \\
\text { United States Department of Commerce } \\
5285 \text { Port Royal Road } \\
\text { Springfield, Virginia } 22161\end{array}$}} \\
\hline & \\
\hline & \\
\hline & \\
\hline \multirow{2}{*}{\multicolumn{2}{|c|}{$\begin{array}{l}\text { NTIS Price Codes } \\
\text { Microfiche A01 }\end{array}$}} \\
\hline & \\
\hline \multicolumn{2}{|c|}{ Printed Copy } \\
\hline & Price \\
\hline Pages & Codes \\
\hline $001-025$ & $\mathrm{~A} 02$ \\
\hline $026-050$ & $\mathrm{~A} 03$ \\
\hline $051-075$ & A04 \\
\hline $076-100$ & A05 \\
\hline $101-125$ & $A 06$ \\
\hline $126-150$ & A07 \\
\hline $151-175$ & $A 08$ \\
\hline $176-200$ & $A 09$ \\
\hline $201-225$ & A010 \\
\hline $226-250$ & A011 \\
\hline $251-275$ & $\mathrm{~A} 012$ \\
\hline $276-300$ & A013 \\
\hline
\end{tabular}


PNL-5906

UC -80

TWO-PHASE ALKALI-METAL

EXPERIMENTS IN REDUCED

GRAVITY

Z. I. Antoniak

June 1986

Prepared for

the U.S. Department of Energy

under Contract DE-AC06-76RLO 1830

Pacific Northwest Laboratory

Richland, Washington 99352 


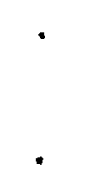




\section{ABSTRACT}

Future space missions envision the use of large nuclear reactors utilizing either a single or a two-phase alkali-metal working fluid. The design and analysis of such reactors require state-of-the-art computer codes that can properly treat alkali-metal flow and heat transfer in a reduced-gravity environment.

Current single and multiphase computer codes rely on the presence of gravity--in the fluid momentum equations, in defining their flow regimes, in specific two-phase flow models, or indirectly in the form of correlations obtained from tests conducted in a $1-\mathrm{g}$ field. New flow regime maps, models, and correlations are required if the codes are to be successfully applied to reduced-gravity flow and heat transfer. A literature search of relevant experiments in reduced gravity is reported on here, and reveals a paucity of data for such correlations. The few ongoing experiments in reduced gravity are noted. General plans are put forth for the reduced-gravity experiments which will have to be performed, at NASA facilities, with benign fluids.

A similar situation exists regarding two-phase alkali-metal flow and heat transfer, even in normal gravity. Existing data are conflicting and inadequate for the task of modeling a space reactor using a two-phase alkalimetal coolant. The major features of past experiments are described here. Again, general plans are made for future alkali-metal experiments in normal gravity.

Data from the reduced-gravity experiments with innocuous fluids are to be combined with normal gravity data from the two-phase alkali-metal experiments. Analyses undertaken here give every expectation that the correlations developed from this data base will provide a valid representation of alkali-metal heat transfer and pressure drop in reduced gravity. 



\section{CONTENTS}

1.0 INTRODUCTION . . . . . . . . . . . . . . . 1.1

2.0 OVERVIEW OF COMPUTER CODE APPLICATIONS . . . . . . . 2.1

2.1 SINGLE-PHASE AND HOMOGENEOUS TWO-PHASE CODES . . . . . 2.1

2.2 TWO-PHASE MULTIFIELD CODES ..................... 2.3

3.0 RATIONALE FOR EXPERIMENTS . . . . . . . . . . . . 3.1

3.1 EXPERIMENTS IN REDUCED-GRAVITY ENVIRONMENTS . . . . . 3.1

3.2 TWO-PHASE ALKALI METAL EXPERIMENTS .............. 3.2

4.0 REDUCED-GRAVITY EXPERIMENTS . . . . . . . . . . . 4.1

4.1 FACILITIES AVAILABLE FOR REDUCED-GRAVITY EXPERIMENTS . . . 4.1

4.1 .1 Drop Towers and Tubes ............ 4.1

4.1 .2 Aircraft ..................... 4.3

4.1 .3 Rocket ..................... 4.4

4.1 .4 Shuttle..................... 4.5

4.1 .5 Magnetic Field . . . . . . . . . . 4.6

4.1 .6 Summary and Conclusions ........... 4.7

4.2 PAST REDUCED-GRAVITY EXPERIMENTS . . . . . . . . . . 4.8

4.2.1 Classification of Tests by Facility ...... 4.9

4.2 .2 Conclusions .................. 4.15

4.3 CURRENT AND PLANNED REDUCED-GRAVITY EXPERIMENTS . . . . . 4.15

4.3 .1 NASA Plans .................. 4.15

4.3.2 University Activities . . . . . . . . . 4.17

4.3 .3 Industry Activities . . . . . . . . . 4.18

4.4 PROPOSED TWO-PHASE REDUCED-GRAVITY EXPERIMENTS . . . . . 4.19 
4.4.1 Approach ................. 4. 4.20

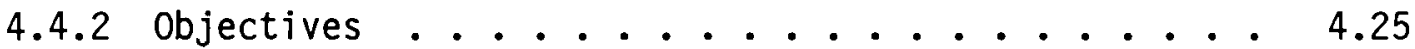

4.4.3 General Plans............... 4.27

4.4.4 Conclusions and Recommendations ......... 4.28

5.0 ALKALI METAL EXPERIMENTS IN GRAVITY FIELDS . . . . . . . 5.1

5.1 PAST TWO-PHASE ALKALI-METAL EXPERIMENTS . . . . . 5.2

5.1.1 Oak Ridge National Laboratory (ORNL) . . . . . 5.2

5.1 .2 Los Alamos National Laboratory (LANL) . . . . . 5.3

5.1.3 Argonne National Laboratory (ANL) . . . . . . 5.3

5.1.4 Hanford Engineering Development Laboratory (HEDL) . . 5.4

5.1 .5 others ........................ 5.4

5.1 .6 General Electric Company (GE) . . . . . . 5.5

5.1.7 Conclusions and Recommendations ........ 5.6

5.2 PROPOSED TWO-PHASE ALKALI-METAL EXPERIMENTS (IN GRAVITY FIELDS) 5.8

5.2.1 Approach . . . . . . . . . . . 5.8

5.2 .2 objectives ...................... 5.9

5.2.3 General Plans............... 5.11

5.2.4 Conclusions and Recommendations ......... 5.11

6.0 SUMMARY AND CONCLUSIONS ......................... 6.1

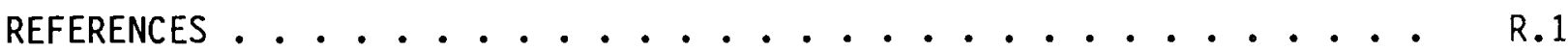




\section{FIGURES}

4.1 Typical "Low Gravity" Trajectory for Learjet . . . . . . . . 4.3

4.2 Two-Phase Reduced-Gravity Experimental Task Flow . . . . . . 4.29

6.1 Two-Phase Alkali-Metal Experiment Task Flow . . . . . . . . . 6.2 


\section{TABLES}

2.1 Code Assessment and Changes Required for Modeling 0-g Convection 2.4

4.1 Experimental Facilities and Techniques for Attaining $A$ Reduced-Gravity Environment . . . . . . . . . . 4.8

4.2 Reduced Gravity Two-Phase Convection Experiments . . . . . . 4.16

4.3 Candidate Fluid Properties . . . . . . . . . . . . 4.22

4.4 Comparison of Candidate Fluids at $\mathrm{G}=1000$. . . . . . . . 4.23

4.5 Comparison of Candidate Fluids at constant Re . . . . . . . . 4.24

4.6 Test Approach Options and Ratings . . . . . . . . . . . 4 4.26

5.1 Survey of Representative Boiling Liquid-Metal Tests . . . . . 5.7 


\section{NOMENCLATURE}

\section{Roman Letters}

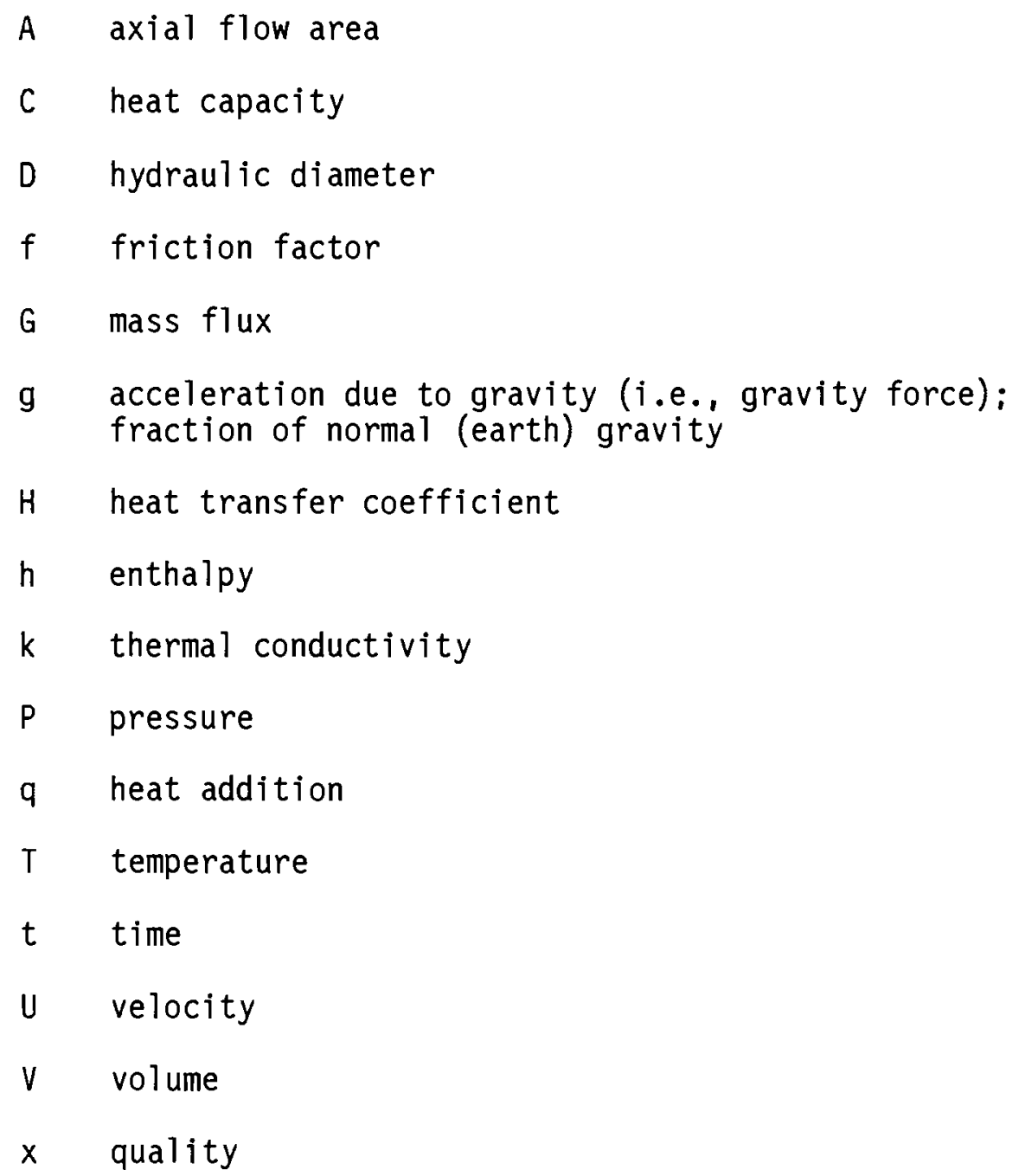


$\rho$ density

$\sigma \quad$ fluid-fluid stress; surface tension

$\tau \quad$ frictional drag

$\phi^{2} \quad$ two-phase multiplier

\section{Subscripts}

$f$ fluid (either liquid or vapor)

g saturated vapor (i.e., gas)

I interfacial

e liquid

P pressure

$\checkmark \quad$ vapor

W wall

Symbols

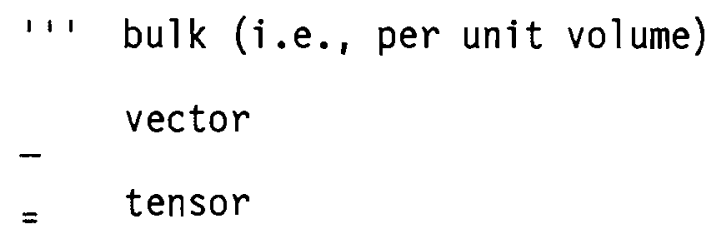

Operators

$\nabla$ - divergence of a vector field 


\begin{tabular}{|c|c|c|c|}
\hline Name & Symbol & Definition & Significance \\
\hline Reynolds & $\operatorname{Re}$ & $\frac{\rho U^{2} / D}{\mu U / D^{2}}=\frac{U D}{\nu}$ & $\frac{\text { Inertial }}{\text { Viscous }}$ forces \\
\hline Froude & $\mathrm{Fr}$ & $\frac{\rho U^{2} / D}{\rho g}=\frac{U^{2}}{D g}$ & $\frac{\text { Inertial }}{\text { Gravity }}$ forces \\
\hline Weber & We & $\frac{\rho U^{2} / D}{\sigma / D^{2}}=\frac{\rho U^{2} D}{\sigma}$ & $\frac{\text { Inertial }}{\text { Surface tension forces }}$ \\
\hline Bond & Bo & $\frac{W e}{F r}$ & $\frac{\text { Gravity }}{\text { Surface tension forces }}$ \\
\hline Peclet & $\mathrm{Pe}$ & $\operatorname{Re} \bullet \operatorname{Pr}$ & $\frac{\text { Bulk }}{\text { Conductive }}$ heat transport \\
\hline Prandt 1 & $\mathrm{Pr}$ & $\frac{c_{p}^{\mu}}{k}$ & $\frac{\text { Momentum }}{\text { Thermal }}$ diffusivity \\
\hline
\end{tabular}




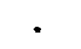

• 
TWO-PHASE ALKALI-METAL EXPERIMENTS

IN REDUCED GRAVITY

\subsection{INTRODUCTION}

The Pacific Northwest Laboratory (PNL) of the Department of Energy (DOE) has been assigned the role of modeling the thermal-hydraulics of advanced multimegawatt (MMW) nuclear reactors. Various reactor concepts are being proposed by other DOE National Laboratories, by industry, and by universities. This document addresses the experimental requirements posed by one concept--where the reactor working fluid is a boiling alkali metal. Because neither the organizations nor the sites of the projected experiments have been selected yet, the ensuing discussion is purposely kept very general in recommending approaches and plans.

Future space missions envision the need for high power levels (up to hundreds of MWe), which are orders of magnitude greater than required by spacecraft launched previously. The concept that appears to have the best potential for supplying such power is a nuclear reactor-based one, with a heat engine and alternator providing the conversion of thermal to electrical power. Stringent weight, heat transfer, and compactness criteria lead to the use of an alkali metal heat transfer medium, with a boiling alkali metal (BAM) system offering significant advantages over a single-phase system with an intermediate heat exchanger. In any event, there is a crucial need for analytical tools that can simulate two-phase flows in a zero gravity $(0-\mathrm{g})$ or variable gravity environment. Mature computer codes exist that consider singlephase liquid metal flow and two-phase steam-water flow, both in normal gravity. To be completely useful for the design and analysis of BAM reactors these codes will need to be modified to handle boiling alkali metals instead of water and to do it in variable gravity. Experimental 0-g two-phase flow data are needed to provide new models and correlations for flow regimes, drag, and heat transfer. 
Data on alkali metal two-phase forced convection in a normal gravity field are extremely limited; reduced-gravity data are practically nonexistent (only mercury condensation has been studied somewhat). However, reduced-gravity experiments with two-phase flow of more common fluids (e.g., water, air/water, halocarbons) have been more numerous. A comprehensive literature survey of these experiments has been completed. Results of this survey indicate that both the nature of boiling alkali metal and reduced-gravity experiments, and the acquired data, have been limited in various ways. Thus, the utility of these past experimental efforts to the design and analysis of a space reactor is marginal.

The discussion here begins with an overview of the status of single and multiphase computer codes. This is not a detailed evaluation of specific codes, but rather an assessment of the capabilities of the available code types. The intent here is to illustrate code application of the reduced-gravity data and correlations and to highlight those terms most sensitive to changes in the gravity field. 


\subsection{OVERVIEW OF COMPUTER CODE APPLICATIONS}

Core thermal-hydraulic codes have been developed for single-phase alkalimetal and limited boiling alkali-metal systems for the Liquid Metal Fast Breeder Reactor (LMFBR) Program. Two-phase multifield simulation codes have been developed for the water reactor industry. Others have been available for some time to analyze commercial and advanced gas-cooled reactors.

The LMFBRs operate with single-phase sodium systems and pin-type fue 1. Boiling-water reactors use pin-type fuel in two-phase flow, but at pressures where the liquid-to-vapor expansion ratio is not severe. In contrast, multimegawatt space reactors using alkali-metal coolants need to operate with liquid or boiling potassium or lithium as coolants, and either pin, wedge, plate, or other complex fuel geometries. All these systems will operate in a 0 - or variable-gravity environment, which complicates thermal-hydraulic analysis, especially for two-phase systems.

Existing computer codes must be modified before they can provide accurate results at $0-g$. If one were to eliminate gravity by inputting $g=0$, and/or changing $g$ to 0 in all equations (not $g_{C}$, the conversion constant), mixed results would ensue, depending on the code. The simpler single-phase or homogeneous two-phase codes might provide reasonably good results; the more complex multifield two-phase codes would probably not fare as well. This is discussed in greater detail below.

\subsection{SINGLE-PHASE AND HOMOGENEOUS TWO-PHASE CODES}

All single-phase and homogeneous two-phase codes could easily be modified for $0-g$ flow modeling. The g-field term would have to be set to zero wherever it occurs. Other necessary changes would involve the pressure drop and heat transfer correlations applicable to a $0-g$ environment. Not a trivial task, but because the mathematical formulations would not be affected, the requisite code alterations would be minimal. 
A brief look at the governing equations is instructive. The three equations defining conservation of mass, momentum, and energy have several terms that are, directly or indirectly, dependent upon gravity.

Conservation of Mass

$$
\frac{\partial \rho}{\partial t}+\nabla \cdot(\rho \underline{U})=0
$$

Conservation of Momentum

$$
\frac{\partial}{\partial t}(\rho \underline{U})+\nabla \cdot(\rho \underline{U U})=\frac{f \phi^{2} P_{W}}{A} \rho U^{2}-\Delta P+\rho g
$$

\section{Conservation of Energy}

$$
\frac{\partial}{\partial t}(\rho h)+\nabla \cdot(\rho h \underline{U})=\frac{H A}{V}\left(T_{W}-T_{f}\right)-\nabla \cdot k \nabla T
$$

For example, in Equation (2.2) the friction factor, $f$, and its two-phase multiplier, $\phi^{2}$, are gravity-dependent, and the gravity force has an explicit g present. In Equation (2.3), the convective heat transfer coefficient, $H$, can be somewhat gravity-dependent also. Setting $g=0$, and inputting correlations or values for $f, \phi^{2}$, and $H$ which correspond to a $0-g$ environment, should account for all the $0-g$ effects. The major portion of this task then lies in experimental determination of $f, \phi^{2}$, and $H$, with code changes and inputs accounting for only a small portion of the task.

Modeling of a $0-g$ environment with these codes as-is, without any of the changes noted above, would likely result in fairly reasonable answers. The chief limitation here, as for $1-g$ flows, is the simplicity of the single-phase and homogeneous mixture representations, which restricts the applicability of 
such codes. Purely single-phase results would be basically unaffected except for very slight trends. Aside from this, uncorrected reduced-gravity twophase results would probably have too low a pressure drop, and a too-high heat transfer rate. Two-phase flow experiments performed in reduced gravity exhibit a pressure drop significantly greater than at $1 \mathrm{~g}$. The lack of buoyancy at $0 \mathrm{~g}$ suggests that the overall heat transfer coefficient will be decreased thereby, because no free convective mechanisms will operate. At high velocity, little discernible difference should exist between reduced and normal-gravity flows as modeled by single-phase and homogeneous codes. Table 2.1 summarizes the foregoing code evaluations.

\subsection{TWO-PHASE MULTIFIELD CODES}

All codes modeling two separate phases require a much greater expenditure of time and effort in order to adapt them for $0 \mathrm{~g}$ flows. The basic equations of momentum and energy transport would have to be examined, and any g terms set to zero. The flow regime map would have to represent $0-g$ conditions, and experimental data is the absolute determinant of such correlations. Also, changes to the interphase drag and heat and mass transfer calculations would surely be necessary, although it is hoped that the flow regime changes would mitigate this need.

Again, a look at the governing conservation equations yields some insight. At least three equations for each phase defining conservation of mass, momentum, and energy have terms that are, directly or indirectly, dependent upon gravity. Compared to the single-phase and homogeneous two-phase codes, more such terms are present. Shown is an equation set for the vapor component of a six-equation system. Similar considerations exist for nine- and twelve-equation systems. Conservation of Mass

$$
\frac{\partial}{\partial t}\left(\alpha_{v} \rho_{v}\right)+\nabla \cdot\left(\alpha_{v} \rho_{v} \underline{U}_{v}\right)=\Gamma^{\prime} \cdot \cdot
$$


IABLE 2.1. Code Assessment and Changes Required for Modeling 0-g Convection

\begin{tabular}{|c|c|c|c|c|c|c|c|}
\hline \multirow{4}{*}{$\begin{array}{l}\text { Code Linits } \\
\text { Ne. Phases }\end{array}$} & \multirow{4}{*}{$\begin{array}{l}\text { Validity of } \\
\text { Uncorrected' } \\
\text { Run at } \theta\end{array}$} & \multirow{2}{*}{\multicolumn{2}{|c|}{$\begin{array}{l}\text { Estimated Trend } \\
\text { of Uncorrected }\end{array}$}} & \multicolumn{4}{|c|}{ Modifications Required } \\
\hline & & & & \multirow{3}{*}{$\begin{array}{l}\text { Flow } \\
\text { Regine }\end{array}$} & \multicolumn{2}{|c|}{ Friction } & \multirow{3}{*}{$\begin{array}{l}\text { Turbulence } \\
\text { Intensity }\end{array}$} \\
\hline & & \multicolumn{2}{|c|}{ Values of } & & Factor & Heat Transfer. & \\
\hline & & Deltap & $H$ & & Correlation & Cerrelation & \\
\hline 1 & Good $^{(a)}$ & Underpredicted & Overpredicted & No & Yes & Yes & Yes \\
\hline 2 & Good $(b)$ & Underpredicted & Overpredicted & No & Yes & Yes & No \\
\hline Homogeneous & & & & & & & \\
\hline 2, & Poor & Underpredicted & Overpredicted & Yes & Yes $^{(c)}$ & Yes $^{(c)}$ & Yes \\
\hline
\end{tabular}

(a) For single-phase flow.

(b) Where homogeneous representation is applicable.

(c) Magnitude of changes depends on effect of flow regine correlations.

Conservation of Momentum

$$
\frac{\partial}{\partial t}\left(\alpha_{v} \rho_{V} \underline{U}_{v}\right)+\nabla \cdot\left(\alpha_{v} \rho_{v} \underline{U}_{V} \underline{V}_{v}\right)=-\alpha_{v} \Delta P+\alpha_{v} \rho_{v} g
$$

$$
+\nabla \cdot\left(\alpha_{V} \underline{\sigma}_{V}\right)+I_{W V}^{\prime \prime \prime}-I_{I V}^{\prime \prime}{ }^{\prime}+\left(\Gamma+\Gamma^{\prime} \underline{U}\right)
$$

\section{Conservation of Energy}

$$
\frac{\partial}{\partial t}\left(\alpha_{v} \rho_{v} h_{v}\right)+\nabla \cdot\left(\alpha_{v} \rho_{v} h_{v} V_{v}\right)=-\nabla \cdot\left(\alpha_{v} q_{v}\right)+\Gamma \cdot \Gamma^{\prime} h_{g}+q_{I v}^{\prime \prime \prime}+q_{w v}^{\prime \prime \prime}
$$


The momentum equation, Equation (2.5), requires $0-\mathrm{g}$ correlations for the interfacial and wall drag terms $I_{W v}^{\prime \prime \prime}$ and $I_{I V}^{\prime \prime}{ }^{\prime}$. Furthermore, the average rate of vapor generation per unit volume, $\Gamma^{\prime \prime}$, in all equations is gravitydependent ( $v i$ a the interfacial heat fluxes), and a $0-g$ correlation for it must be developed. The g-containing term is, of course, set to zero.

The energy equation, Equation (2.6), also incorporates a $\Gamma^{\prime \prime}$ term. In addition, the interfacial and wall heat fluxes per unit volume ( $q_{I V}^{\prime \prime}$ ' and $q_{w v}^{\prime \prime}$ ', respectively), which are representative of the heat transfer rates, need to be modified.

These changes to account for a $0-g$ environment are the obvious ones. Some less obvious code modifications may be needed as the changes are implemented. What comes to mind is the potential for difficulties in solution. Code stability, convergence, and such critical parameters as cell size, may be affected by the noted changes. Only a more thorough examination of the code(s) chosen for modification can satisfy these concerns. 
- 


\subsection{RATIONALE FOR EXPERIMENTS}

Experiments are usually expensive and time-consuming activities. Justification for certain experimental tasks is provided below.

\subsection{EXPERIMENTS IN REDUCED-GRAVITY ENVIRONMENTS}

As was pointed out, new code features and correlations will be required for analyzing reduced-gravity phenomena. The correlations cannot be derived from first principles and theoretical considerations alone. The state of the art in understanding two-phase flows is fairly rudimentary, necessitating heavy reliance on empirical correlations. These correlations are frequently very situation-specific and thus applicable only to particular fluids and fairly narrow ranges of conditions. This deficiency is evident from the numerous extant pressure-drop and heat-transfer correlations attempting to represent boiling in a gravity field (Hetsroni 1982; Hsu and Graham 1976). clearly, correlations that are not completely successful in predicting behavior over ranges of conditions for which they were developed cannot be extended to represent reduced-gravity conditions with any confidence.

There is also no assurance that even the expected trends (presented in Table 2.1) will hold in reduced gravity. They appear to be reasonable assumptions--but assumptions they remain until verified by experiments. But the experiments performed to date (see Section 4.2) only hint at possible trends--such as flow regime shifts and concomitant increased pressure drop in reduced gravity.

The codes modified to analyze reduced-gravity boiling must do so with a high degree of accuracy. The accuracy is demanded by two ineluctable considerations: weight and safety. Launch costs being considerable, a space reactor design must make efficient use of material in meeting its goals. And, as with any nuclear reactor, safety of operation under all circumstances is of primary concern. These needs can be met only with an experimental program dedicated to obtaining reproducible data with selected fluids, over broad 
operating ranges, in suitable reduced-gravity environments. The only alternative (and an unacceptable one) is to enormously overdesign the first space reactors, and use them as research tools to evolve an optimized design.

\subsection{TWO-PHASE ALKALI METAL EXPERIMENTS}

Boiling phenomena associated with low-Prandtl-number fluids (e.g., alkali metals) differ substantially from those of higher-Prandtl fluids (e.g, water and gases). Heat transport is by different mechanisms, bubble formation and fluid agitation evince different characteristics, and interaction with the container surface (i.e., wettability) is a potential problem. Past alkali metal experiments in 1-g have not accurately quantified parameters such as wall superheat $\Delta T$, critical heat flux, or flow regimes. Although some of the data obtained with low-Prandtl fluids may be applicable to alkali metal boiling, it is not evident a priori which data can be utilized in this manner--especially when the issue is confounded by reduced-gravity effects.

Unless a considerable amount of two-phase alkali metal experimental data is generated, there will remain a lack of confidence in the application and relevance of data from other fluids. Although it is impractical to perform all the experiments (particularly in $0-g$ ) with alkali metals, a number of experiments, both in $1-g$ and $0-g$, must be done using an alkali metal. 


\subsection{REDUCED-GRAVITY EXPERIMENTS}

Two-phase experiments in reduced gravity require specialized facilities and equipment. Past tests have used a number of earth-based facilities, and various fluids including a liquid metal.

\subsection{FACILITIES AVAILABLE FOR REDUCED-GRAVITY EXPERIMENTS}

Ideally, a manned, orbiting space station would be available with extensive laboratory facilities for reduced-gravity research. Also, launch costs, as well as the costs of developing space-qualified test hardware, would be reasonable in terms of the resulting data. Neither criterion is met currently. Sma11, low-power experiments can be performed on the shuttle today, albeit with nonhazardous fluids. The competition for the scheduled shuttle flights is keen, and tests must be planned years in advance of actual flight. Sometime in the 1990 s a permanent manned orbiting laboratory may become available (Shelley 1985). At this time it is not clear if any alkali-metal experiments would be permitted there; hazardous materials are taboo on the shuttle. Regarding launch and test development costs, no appreciable cost reduction is foreseen in the near future.

Given the situation described, at best only a few shuttle experiments will be performed within the time frame allotted for two-phase reduced-gravity experiments. For the majority of the experiments, ground-based facilities will have to be employed. These present various limitations--the chief ones being the duration and steadiness of the reduced-gravity environment.

\subsubsection{Drop Towers and Tubes}

Drop towers and tubes are structures purposely built for studying reducedgravity effects. They use a controlled environment and a difference in elevation to produce "free-fall." That is, an object freely falling in a gravitational field (consisting of body forces) has no net forces acting within it (e.g., pressure gradient) and therefore replicates the phenomena one would observe if that self-same object had no external forces whatsoever acting on 
it. In the towers/tubes, the experimental package is released from an elevated position and subsequently arrested at a lower one. The intervening free-fall period is the experimental phase, during which a reduced-gravity environment is present within the experimental module.

Several deficiencies are associated with these facilities. Because the freely falling experiment is constantly accelerating at $9.8 \mathrm{~m} / \mathrm{s}^{2}$, there is an evident limit to a reasonably sized tower or tube. This severely constrains the duration of the experiment. Aerodynamic drag imposes a net force on the experiment. Low g-levels ${ }^{(a)}$ (on the order of $10^{-6}$ ) can be achieved by evacuating the air from the drop tower prior to an experiment. Alternately, drag shields are of some benefit in nonevacuated towers.

While various organizations besides NASA possess drop towers (e.g., the University of Michigan), these towers are generally small. The most accessible facilities are at the NASA Lewis Research Center (LeRC). At LeRC, a 2.2-s nonevacuated drop tower, and a 5.2-s evacuated drop tube ${ }^{(b)}$ (Petrash and Corpas 1973) are available for experiments (the times refer to the duration of the free-fall period). The nonevacuated tower offers quick turnaround so that many experiments $(\leq 9)$ can be performed each day. Its drawbacks are the short freefall time and the relatively high $-g$ environment resulting from aerodynamic drag. The 5.2-s tube overcomes these problems, but because the entire tube must be pumped out (to $\sim 10^{-2}$ torr) between tests, only several experiments are feasible per day. Furthermore, each facility has unique requirements that preclude construction of a single test vehicle acceptable to both the drop tower and tube. It is therefore recommended that experiments be performed in the 5.2-s drop tube.

(a) $g$ is defined as the fraction of normal (earth) gravity, and is the resultant (net) force within the body due to the earth's gravity field. Use of these terms is consistent with engineering terminology.

(b) Vernon, R. W. 1985. Personal communication, November 21, 1985. NASA Lewis Research Center, Cleveland, Ohio. 


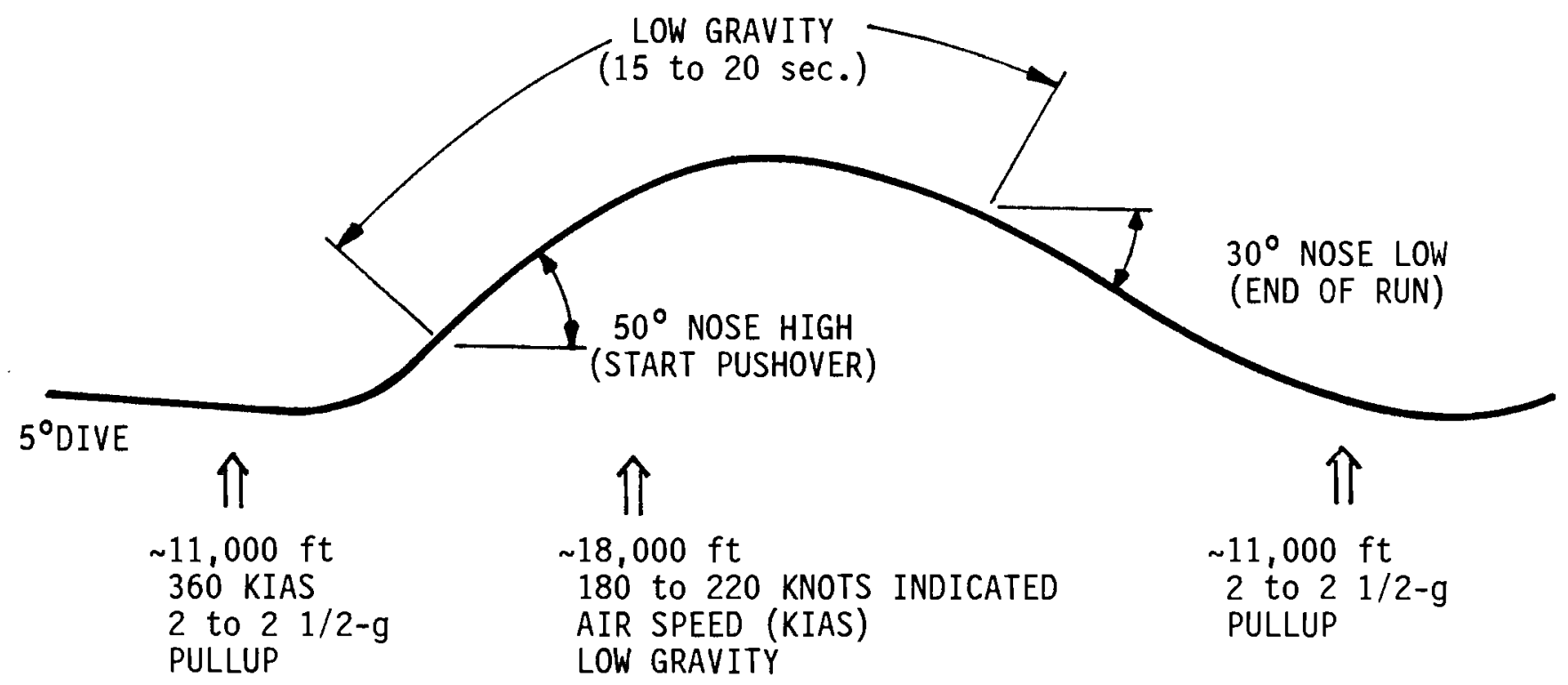

EIGURE 4.1. Typical "Low Gravity" Trajectory for Learjet

\subsubsection{Aircraft}

An aircraft flying a parabolic trajectory (see Figure 4.1) can attain low g-levels. These levels can be sustained considerably longer than those in drop towers because the elevation change during free-fall is much greater. The aircraft also offers significantly more room for an experiment, and power can be drawn from onboard generators, obviating the need for batteries. An additional advantage is that the experimenter can fly along with the experiment and is able to both observe and control the test while it is in progress.

There are disadvantages associated with this mode of reaching reduced gravity. The magnitude and uniformity of the g-level produced is dependent on many factors, the chief one being the skill of the pilot. Note that prior to the free-fall maneuvers an acceleration of about $2-1 / 2 \mathrm{~g}$ is experienced. This acceleration may perturb flow in the test loop, increasing the time 
required to establish steady state once reduced gravity is achieved. If so, the period for taking valid data may be much shorter than the free-fall time.

NASA owns two aircraft dedicated to reduced-gravity research. A Learjet at LeRC is available ${ }^{(a)}$ that is capable of operating for 15 to $20 \mathrm{~s}$ in a freefall mode (see Figure 4.1). It can fly up to six free-fall trajectories per mission. A much larger aircraft, the $\mathrm{KC}-135$, is similarly maintained by the Johnson Space Center (JSC) ${ }^{(b)}$ (Shurney 1982). Somewhat longer free-fall conditions--about 25 s--can be held (Williams, Keshock, and Wiggins 1973). The g-level then may be slightly higher than that experienced by the Learjet. (a) It is therefore recommended that both aircraft be considered if aircraft missions become necessary.

\subsubsection{Rocket}

A rocket can perform essentially the same function as the aircraft described above. Recently, a SPAR VIII rocket was used in a fluids experiment (Wilcox et al. 1981). This rocket provided over 4 minutes of an "average acceleration near zero" (actual g-level was not reported). Because of the hard landing, it appears that only the film record survived intact.

Additional difficulties are encountered in the use of a rocket for reducedgravity experiments. Survival and recovery of the experimental module is certainly an issue. The size of this module is quite restricted by the rocket itself. The transition from high to reduced gravity, noted under aircraft, is accentuated here. It is not clear how low and steady a g-level is within rocket capabilities. And finally, the number of rockets that would have to be expended in any realistic test series could run into the hundreds, or even thousands--a daunting prospect.

(a) Vernon, R. W. 1985. Personal communication. November 21, 1985. NASA Lewis Research Center, Cleveland, Ohio.

(b) Williams, R. 1986. Personal communication, March 6, 1986. NASA Johnson Space Center, Houston, Texas. 
Because of all these negative attributes, rockets are dropped from further consideration at this point. In the future, the option of using a rocket to fly an alkali-metal experiment may have to be reconsidered.

\subsubsection{Shuttle}

The advent of the shuttle presents new opportunities for reduced-gravity and other space-related experiments (Shawhan 1983). Instruments and small experiments can be housed in small storage containers or in the crew's storage lockers. Larger, more complex test apparatus can be rack-mounted at the aftflight-deck or hard-mounted to the shuttle structure within the payload bay. With the Remote Articulator System (RMS) a payload can be maneuvered outward to distances of $15 \mathrm{~m}$.

These features are merely embellishments to the shuttle's unique capability to maintain a reduced-gravity environment for a long time. Thus, shuttle-based fluids experiments can be run until steady-state conditions prevail, and the low unvarying g-level ensures the absence of gravity-dominated phenomena. Yet another advantage of the shuttle over most other facilities is the possibility of involving crew members in operating or controlling the tests.

A full description of shuttle capabilities and requirements must encompass the less attractive features as well. These requirements for an experimental package are rather onerous in terms of development costs, safety considerations, and, of course, the expense of the shuttle flight itself. Any and every experimenter is faced with clearing these time-consuming hurdles. And the extremely conservative safety criteria, meant to guarantee the safety of the crew, preclude the presence of any hazardous materials or conditions in an onboard experiment. These rules may be relaxed somewhat in the future as more experience is accumulated, and perspective is gained on experimental hazards as opposed to launch and flight dangers. It is highly unlikely that any alkali-metal experiments will be permitted onboard the shuttle. Perhaps a free-flying test package, launched from the shuttle, would be acceptable for alkali-metal flow and heat transfer tests. 
Although it represents a significant improvement over the other facilities, the shuttle environment is by no means ideal. The g-level typically present during orbit is $10^{-3}$ to $10^{-4}$; jitter can degrade it to $10^{-2}$. A true microgravity condition $\left(g=10^{-6}\right)$ is achieved only at the shuttle's center of gravity (Salzman 1985). In comparison, the space station of the 1990 s has a $10^{-5}$ to $10^{-6}$ g-level requirement. This space station, which is still being designed, will represent the first true in-space laboratory with extensive power, instrumentation, data acquisition, and computational capabilities. But until its debut, experimenters must look to the shuttle for the best reduced-gravity environment.

\subsubsection{Magnetic Field}

Keeping in mind that the ultimate goal of this experimental series is to obtain data on alkali metal two-phase behavior in reduced gravity, use of the facilities described represents an arduous and complex approach. If possible, one would like to work directly with the alkali metals, on earth--and still obtain valid data. One potential means for doing so is to investigate behavior in high-g $(>1-g)$ fields created mechanically by, for example, a centrifuge. Given data points at $1 \mathrm{~g}$, and various higher g-levels, one is tempted to extrapolate to a $0-g$ condition. But extrapolation is never a reliable technique and can lead to serious error. Extrapolation in this manner to the singularity of a 0 -g situation is not justifiable; there is simply no way to evaluate the results so achieved.

One alternative exists. The fact that alkali metals are excellent conductors of electricity can be used to advantage. A magnetic field can be employed to "levitate" the alkali metal. By proper orientation, the magnetic field can cancel the gravitational body force, producing essentially 0 -g conditions. Of course, the uniformity of this field must be ensured, and Joule heating of the alkali metal must be minimized.

There exists a well known relationship between a magnetic field, an electric current, and a moving conductor. The geometrical relationship among these three parameters is illustrated by the familiar right-hand rule (Sears 
and Zemansky 1962). An electric motor is a typical example of the motion induced in the conductor (armature) by an electric current in a magnetic field (Anderson 1977). A less familiar but more apropos example is the

electromagnetic pump, specifically developed for pumping electrically conductive fluids such as alkali metals (Murray 1961).

For a test section, one can envision a vertical length of pipe entirely within a horizontal magnetic field of the requisite strength to cancel gravity and provide adequate mass flow. Two complications come to mind: 1) assuming heating in the test section, the temperature, and properties, of the alkali metal will vary over the length of the section; and 2) the generation of vapor may introduce anomalies. These effects, and the manner in which they influence the desired cancelation of the gravitational body force, need to be examined in detail to assess the feasibility of this approach.

Only a few experiments have been performed with a boiling liquid metal (mercury) in a magnetic field (Faber and Hsu 1968). These experiments were not intended to investigate a $0-g$ condition, so their results are hardly applicable here.

It is recommended that the use of magnetic fields be investigated further. Enormous benefits would result from earth-based potassium experiments that replicated the conditions in space.

\subsubsection{Summary and Conclusions}

The facilities and techniques for generating reduced-gravity environments are summarized in Table 4.1. It is concluded that several of them would be suitable for future experiments. A study of magnetic field utilization to attain $0 \mathrm{~g}$ is under way at Princeton University, and is funded by PNL. 
IABLE 4.1. Experimental Facilities and Techniques for Attaining A Reduced-Gravity Environment

\begin{tabular}{|c|c|c|c|c|c|}
\hline Type & Features & Special Conditions & $\begin{array}{l}\text { Lowest } \\
\text { g-level } \\
\text { Attainable }\end{array}$ & $\begin{array}{l}\text { Reduced } \\
\text { Gravity } \\
\text { Duration,s }\end{array}$ & Comment \\
\hline Drop & $\begin{array}{l}\text { Various towers/ } \\
\text { tubes ( } 13.2 \text { to } \\
145 \mathrm{~m} \text { high) }\end{array}$ & Vacuum, cryogenic & $\begin{array}{rl}< & 1 \times 10^{-5} \\
& (\text { vac. }) \\
2 & 1 \times 10^{-3} \\
& (\text { nonevac.) }\end{array}$ & $\begin{array}{l}5.15 \\
(10, \text { if } \\
\text { accel. } \\
\text { from } \\
\text { botton) }\end{array}$ & $\begin{array}{l}\text { Time is severe } \\
\text { constraint. High } \\
\text { deceleration rate } \\
\text { (approx. } 36 \mathrm{~g} \text { ) to stop. }\end{array}$ \\
\hline $\begin{array}{l}\text { Magnetic, } \\
\text { viscous, } \\
\text { sonic, } \\
\text { inertial }\end{array}$ & $\begin{array}{l}\text { 'Levitate' } \\
\text { sample }\end{array}$ & -- & Unknown & Days & $\begin{array}{l}\text { Techniques may generate } \\
\text { secondary effects, } \\
\text { disturbing or dis- } \\
\text { torting sample. }\end{array}$ \\
\hline Aircraft & $\begin{array}{l}\text { Repeated para- } \\
\text { bolic trajec- } \\
\text { tories between } \\
\text { two altitudes }\end{array}$ & $\begin{array}{l}\text { Can acconnodate } \\
\text { large payloads }\end{array}$ & 20.61 & approx. 36 & $\begin{array}{l}\text { Relatively high } \\
\text { g-field level; } \\
\text { difficult to maintain } \\
\text { at steady value. }\end{array}$ \\
\hline Rocket & Free-fall mode & -- & Unknown & approx. 250 & $\begin{array}{l}\text { No details provided } \\
\text { in literature. }\end{array}$ \\
\hline $\begin{array}{l}\text { Space lab } \\
\text { (shutt/e) }\end{array}$ & $\begin{array}{l}\text { Linited size of } \\
\text { experimental } \\
\text { package }\end{array}$ & $\begin{array}{l}\text { Stringent } \\
\text { safety } \\
\text { requi rements }\end{array}$ & $\begin{array}{l}1 \times 10^{-2} \\
-1 \times 10^{-6} \\
\text { (jitter-free, } \\
\text { on center of } \\
\text { gravity) }\end{array}$ & Days & $\begin{array}{l}\text { Long scheduling } \\
\text { lead time. Crew } \\
\text { members can be used } \\
\text { to 'run" experiments. }\end{array}$ \\
\hline
\end{tabular}

(a) Fraction of earth gravity.

(b) While these techniques generally do not provide truly 0 -g conditions, they may be of some utility here and are included for completeness. Gravity fields $>1$ can be attained by inertial techniques, while near $0-g$ conditions are possible through use of magnetic fields.

\subsection{PAST REDUCED-GRAVITY EXPERIMENTS}

The scope and extent of experiments in two-phase reduced-gravity flows have been determined largely by the methods and facilities employed for producing the reduced gravity. The readily available means (e.g., drop test, 
aircraft flying parabolic trajectories) have seen the greatest use; closer approximations to a long-term microgravity environment (e.g., rocket, Skylab) have rarely been employed. This has severely restricted the quality and quantity of the data. The chief restrictions are in the minimum gravity field level attained by a particular means and in the duration of this field. Additional constraints on the types of fluid, size of the experimental package, power available to run the experiment, and instrumentation and data acquisition equipment have exerted a negative influence on the nature of the experiments. As a result, the operable mechanisms in reduced-gravity two-phase convection have not been elucidated, nor have quantitative heat transfer and hydrodynamic correlations been developed. The data are generally more qualitative than quantitative and suggestive of the improvements needed to obtain valid results. No criticism of these past efforts is implied, as they were the first research steps taken in charting an unknown field. These efforts will now be discussed in some detail.

\subsubsection{Classification of Tests by Facility}

\subsubsection{Drop Tests}

Recently, growth of single bubbles in microgravity $\left(10^{-4}\right.$ to $\left.4 \times 10^{-2} \mathrm{~g}\right)$ has been studied by Cooper, Judd, and Pike (1978). Water, toluene, and hexane have been separately examined, under no-flow conditions. With the liquid in a saturated state, a single bubble was initiated at the wall by electrical means and its growth recorded with a high-speed camera. From the record, a simple expression was developed, governing the growth of diffusion-controlled bubbles. No sudden departure of the bubbles from the wall was observed; the lack of large temperature gradients was presumably responsible. The shapes of bubbles were found to be functions of surface tension, rate of growth, time, and the microgravity field. A relationship was also found between the maximum bubble diameter at departure from the wall and the gravitational field. Surface tension was observed to aid bubble departure by rounding-off bubbles.

Another experimental study (Labus, Aydelott, and Lacovic 1972) examined the proportion of vapor generated at the surface of saturated Refrigerant 11, 
and in the bulk liquid (i.e., bubbles), upon venting to vacuum. The 5-s droptest facility was used with a photographic record plus some instrumentation such as pressure transducers and a thermistor. No bulk vapor was generated at $0 \mathrm{~g}$ (i.e., all of the vapor was generated at the surface); small amounts of bulk vapor (boiling) were generated at measurable gravity levels. The vent rate, the percentage of vapor by volume, and the Bond number (defined as the ratio of acceleration to capillary forces) strongly influenced the amount of bulk vapor generated.

An earlier experimental program (Cochran 1970) studied forced-convection boiling at low heat flux and low velocities in microgravity. The liquid used was slightly subcooled $\left(0.4\right.$ to $\left.1.5^{\circ} \mathrm{C}\right)$ distilled water, heated from below with a flat Chromel strip. Temperature was measured by a thermistor, and a 900frame-per-second camera recorded the dynamics during the 2.2-s free-fall. Bubble growth exhibited a cyclical trend; it is not clear if steady-state conditions prevailed. The majority (85\%) of the bubbles remained attached to the heater surface, essentially forming a bubble boundary layer. The bubble diameter was found to correlate well with saturation layer thickness. The relevance of this work is probably restricted to storage tanks containing cryogenic fluids.

A very similar series of experiments by Cochran, Aydelott, and Spuckler (1967) considered several fluids, but with no forced convection. The amount of subcooling was varied, as was the heat transfer rate; the effects on bubble size and lifetime with gravity field were noted. The basic physical principles governing bubble dynamics were used in obtaining simple expressions for the dominant forces acting on the bubbles. These forces were calculated and plotted versus time.

Bubble size and lifetime in water were found to be nearly independent of the gravity field at high subcooling. For low subcooling, larger bubbles developed in $0 \mathrm{~g}$ than in $1 \mathrm{~g}$. An ethanol/water solution, with a surface tension about $30 \%$ that of water, showed little influence of either g-field or subcooling. The results are attributed to the more nearly spherical shape of 
the solution bubbles, compared to water. The pressure force therefore dominated solution bubble dynamics. A variation in heat transfer rate (from 24,800 to $114,000 \mathrm{Btu} / \mathrm{h}-\mathrm{ft}^{2}$ ) for this solution also exhibited no trends with g-field on bubble radii and lifetimes. These findings may prove significant when the choice of a fluid for the boiling reactor is made. Tests with a sugar/water solution having a viscosity ten times that of water gave results similar to water regarding gravity and subcooling effects on bubble radii and lifetimes. But the force histories for water and the sucrose solution are vastly different, with a significant drag force in the latter.

Oker and Merte (1973) performed an elaborate series of pool boiling tests using liquid $\mathrm{N}_{2}$ and Freon 113 and heat flux from $1 \times 10^{3}$ to $1 \times 10^{5} \mathrm{~W} / \mathrm{m}^{2}$. A rather short drop tower was used, which gave $\langle 1.4 \mathrm{~s}$ of free-fall; it is uncertain if steady-state conditions ever prevailed during the test. The glevel was fairly high, up to $4 \times 10^{-3}$. The data indicate that surface superheat at boiling inception is a function of gravity and is claimed to be less at $0-g$ than in normal gravity. But an examination of the data shows that generally the $\Delta T$ increased significantly in the transition from normal to 0 -g--which is what one would expect, as the buoyancy force driving natural convection heat transfer vanishes at $0 \mathrm{~g}$. This study also shows a summary table, listing earlier nucleate pool-boiling reduced-gravity experiments and heat transfer trends. These trends appear to be somewhat contradictory.

A review article by Siegel (1967) discusses and summarizes data on pre1967 reduced-gravity experiments. Most experiments used the drop tower facilities, although some also utilized aircraft. For pool boiling, the critical heat flux between 0.01 and $1 \mathrm{~g}$ was found to correlate well with $\mathrm{g}^{1 / 4}$. Whether this flux goes to zero at $0 \mathrm{~g}$ could not be determined from the level and duration of the g-field achievable then. Short-duration saturated pool nucleate boiling seems independent of gravity, but requires substantiation. Insufficient data existed for drawing any conclusions regarding forced convection heat transfer. Some condensation results are also reported. 
The early work, while important in initiating this study area, addressed only a fraction of the issues presented by $0-g$ boiling. This early work cannot be relied upon to provide definitive models or results.

\subsubsection{Aircraft Tests}

A fairly recent experiment delved into the topics of flow regimes and pressure drop (Heppner, King, and Littles 1975). Two-phase flow of air and water in a circular channel was examined first on earth, then in an aircraft simulating $0 \mathrm{~g}$ for about $20 \mathrm{~s}$ per trajectory. Analysis indicated a downward shift of regime boundaries at reduced gravity; i.e., at a given quality, the transition from distributed + segregated $\rightarrow$ segregated + intermittent flow ought to occur at a lower total mass flow rate in reduced gravity. (a) Initial testing confirmed this trend, but not its magnitude. However, a repeat test inexplicably nearly agreed with the analytical predictions. As for $\Delta P$, the 0 -g pressure drop is significantly higher than that for $1 \mathrm{~g}$ and is ascribed to the change in flow regime noted earlier--which itself was a consequence of increased turbulence in $0 \mathrm{~g}$. If generally true, the added $\Delta P$ could have a considerable impact on a space reactor and needs to be investigated much more rigorously.

A similar experimental effort was devoted to condensation of Freon-12 (Williams 1974; Keshock et al. 1974; Williams, Keshock, and Wiggins 1973). Although the test section was well instrumented, only qualitative results are reported. It appears that the flow regimes observed (photographic record) conform reasonably well to Baker-chart predictions (Collier 1972, p. 18). The flow at $0 \mathrm{~g}$ was notably less irregular than at $1 \mathrm{~g}$, which is somewhat at variance with the trend noted above. Based on little discernible difference in condensation lengths, it was also hypothesized that heat transfer was unaffected by g-level.

(a) Distributed flow assumes one phase to be continuous, the other phase need not be distributed over the same section of pipe; segregated flow occurs when the gas and liquid phases are continuous in the axial direction; intermittent flow results when the phases form alternating pockets across the tube. 
Some preliminary studies used mercury in reduced-gravity condensation experiments. Albers and Macosko (1965) reported practically the same pressure losses at $1 \mathrm{~g}$ and $0 \mathrm{~g}$, in a constant-diameter tube. Both losses were greater than predicted by the Lockhart-Martinelli correlation (Collier 1972, p. 35) at low vapor qualities. But in the high-quality region of the condensing tube, the pressure drop from the Lockhart-Martinelli correlation agreed within $\pm 70 \%$ with the measured pressure loss. It was felt that fog-flow theory, which postulates re-entrainment of condensed droplets back into the vapor stream, best explained the data (visualization was not possible in the stainless steel test section).

A photographic experiment conducted by Namkoong et al. (1967) with mercury vapor condensing in glass tubes failed to support the fog-flow hypothesis. In tubes with diameters $\geq 1 \mathrm{~cm}$, the distribution of drops in the wall was concentrated on the tube bottom in $1-g$ conditions. Zero-g conditions led to a uniform distribution of droplets, both in the droplet stream and at the wall.

Mercury differs so enormously from the alkali metals (especially regarding wetting of the heat transfer surface) that it is not at all certain that the above studies have any relevance to alkali metal two-phase flows. The main advantage in using mercury as an experimental fluid lies in its low melting temperature.

\subsubsection{Rocket Tests}

A 4-min rocket flight provided the microgravity environment for an experiment on bubble migration in molten glass ("fining") as reported by wilcox et al. (1981). A platinum heating strip melted a sample of sodium borate glass, which contained entrapped voids. During the 0 -g portion of the flight, distinct migration of the bubbles toward the hotter portion of the sample was noted. This observation is in agreement with the Brown model (Collier 1972, p. 165) of thermocapillary bubble migration, which predicts motion against a thermal gradient. 


\subsubsection{Shuttle Tests}

The shuttle program envisions a series of fluid mechanics experiments (NASA 1984). To this end, a Drop Dynamics Module and a Geophysical Fluid Flow Cell have been constructed for use in the payload bay. The former module was flown in 1985, and tests studying the dynamics of rotating and oscillating free drops have been done. No flow experiments have been performed on the shuttle to date.

\subsubsection{Magnetic Field Tests}

Several experiments have been performed with magnetic fields and a liquid metal (mercury). The objective was not to counteract gravity, but rather to note any perturbations engendered by the field on the boiling process. Faber and Hsu (1968) applied a vertical magnetic field of 1 to 6 tesla to mercury undergoing nucleate pool boiling on a horizontal surface. Test results suggest that the magnetic induction encourages the incipience of boiling; i.e., boiling can be initiated at a lower heat flux in the presence of the field than without it. But a simultaneous reduction in heat transfer was observed. It was postulated that the retarding influence of the Lorentz force increases bubble population, and inhibits bubble motion (i.e., buoyancy is reduced) and agitation. Analysis indicated that the growing bubbles become elongated spheroids, with the major axis aligned with the magnetic field. These mechanisms were thought to be the chief contributors to the observed effects.

An earlier experiment, reported by Hsu and Graham (1976), had the magnetic field oriented horizontally. Heat transfer was little perturbed thereby.

Petukhov and Zhilin (1973) discuss a number of experiments performed with single-phase liquid metals in magnetic fields. Both transverse and longitudinal magnetic fields served to inhibit heat transfer. The effect was Reynolds-number-dependent, with the Nusselt number decreased up to $30 \%$ at intermediate values of the Reynolds number. It was suggested that the magnetic fields affect the turbulence, but its exact structure (e.g., vortices in transverse fields) was not elucidated. In any case, these mechanisms may be relatively unimportant in two-phase flows. 
The applicability of the experiments noted to the situation of interest (reduced gravity accomplished by means of a magnetic field) is probably remote. First, the action of various mechanisms was postulated, not proven. Second, an electric current flowing through an alkali metal, causing it to flow vertically within a horizontal magnetic field, represents a significantly different situation from the pool boiling studies. So the postulated mechanisms, even if valid, may be inoperable in a flow condition. All these issues need to be investigated more fully; analytical studies and small experiments ought to prove or disprove the merit of magnetic fields as a means for generating reduced-gravity.

\subsubsection{Conclusions}

A survey of past reduced-gravity two-phase convection experiments has disclosed a great need for more and better data. Past experiments are useful to the current effort more as guideposts than as sources of hard data. A brief summary of the chief $0-g$ experiments is provided in Table 4.2.

\subsection{CURRENT AND PLANNED REDUCED-GRAVITY EXPERIMENTS}

Although a large number of reduced-gravity experiments are being planned or proposed, only a few are actually in progress. The costs and complexities associated with such experiments are effective deterrents to wide participation. While some interest has been stirred in the private sector by NASA urgings, nothing substantive has been accomplished with private funds. It appears that, until industry sees a clear benefit from reduced-gravity experiments, only meager attention will be given this area. One of the difficulties with assessing reduced-gravity experiments is lack of information; there is no central repository or clearinghouse on active programs.

\subsubsection{NASA Plans}

A variety of fluids and fluids-related experiments are proposed in NASA documents (NASA brochure, undated; Pentecost 1983, 1984; Naumann 1982). Only 


\section{IABLE 4.2. Reduced Gravity Two-Phase Convection Experiments}

\begin{tabular}{|c|c|c|c|c|c|c|c|c|}
\hline Iype & Investigated & Eluids & Elow & Iransfer & Wiquid State & Conclusions & Comment & Reference \\
\hline $\begin{array}{l}\text { Drop } \\
\text { test }\end{array}$ & $\begin{array}{l}\text { Single bubble } \\
\text { growth }\end{array}$ & $\begin{array}{l}\text { Water, } \\
\text { toluene, } \\
\text { hexane }\end{array}$ & No & Not examined & Saturated & $\begin{array}{l}\text { Siaple correla- } \\
\text { tions found for } \\
\text { growth and shape } \\
\text { with } g \text { as } \\
\text { paraneter }\end{array}$ & $\begin{array}{l}\text { Not directly } \\
\text { useful for } \\
\text { present needs }\end{array}$ & $\begin{array}{l}\text { Cooper, Judd, } \\
\text { and Pike (1978) }\end{array}$ \\
\hline $\begin{array}{l}\text { Drop } \\
\text { test }\end{array}$ & $\begin{array}{l}\text { Vapor genera- } \\
\text { tion at } \\
\text { liquid sur- } \\
\text { face and in } \\
\text { bulk fluid }\end{array}$ & $\begin{array}{l}\text { Refriger- } \\
\text { ant } 11 \\
(R-11)\end{array}$ & No & Not exara ined & Saturated & $\begin{array}{l}\text { No vapor gener- } \\
\text { ated (i.e., } \\
\text { bubbles) in } \\
\text { bulk liquid } \\
\text { upon venting } \\
\text { at } \mathrm{g}\end{array}$ & Not relevant & $\begin{array}{l}\text { Labus, Aydelott, } \\
\text { and Lacovic (1972) }\end{array}$ \\
\hline $\begin{array}{l}\text { Drop } \\
\text { test }\end{array}$ & $\begin{array}{l}\text { Forced } \\
\text { convection } \\
\text { boiling at } \\
\text { low heat flux } \\
\text { and velocity }\end{array}$ & $\begin{array}{l}\text { Distilled } \\
\text { water }\end{array}$ & Yes & Not examined & $\begin{array}{l}\text { Slightly } \\
\text { subcooled }\end{array}$ & $\begin{array}{l}\text { Simple correla- } \\
\text { tion found for } \\
\text { bubble dianeter } \\
\text { versus evapora- } \\
\text { tion layer }\end{array}$ & Not relevant & Cochran (1970) \\
\hline $\begin{array}{l}\text { Drop } \\
\text { test }\end{array}$ & $\begin{array}{l}\text { Pool boiling. } \\
\text { Effects of } \\
\text { surface } \\
\text { tension, } \\
\text { viscosity, } \\
\text { and subcooling }\end{array}$ & $\begin{array}{l}\text { Water, } \\
\text { ethanol- } \\
\text { water, } \\
\text { sucrose- } \\
\text { water }\end{array}$ & No & $\begin{array}{l}\text { Varied in } \\
\text { some tests }\end{array}$ & $\begin{array}{l}\text { Various } \\
\text { subcoolings }\end{array}$ & $\begin{array}{l}\text { Mater boiling } \\
\text { (i.e., bubble } \\
\text { size) independ- } \\
\text { ent of } g \text {, at } \\
\text { high subcooling }\end{array}$ & $\begin{array}{l}\text { Trends of } \\
\text { interest }\end{array}$ & $\begin{array}{l}\text { Cochran, Aydelott, } \\
\text { and Spuckler (1967) }\end{array}$ \\
\hline $\begin{array}{l}\text { Drop } \\
\text { test }\end{array}$ & $\begin{array}{l}\text { Pool boiling } \\
\text { (nucleate } \\
\text { plus film) }\end{array}$ & Various & Yes & Yes & Various & $\begin{array}{l}\text { Critical flux } \\
\text { propprtional } \\
\text { to } 9\end{array}$ & $\begin{array}{l}\text { Preliminary } \\
\text { results; } \\
\text { g fields high } \\
\text { (approx. } 0.01 \text { ) }\end{array}$ & Siegel (1967) \\
\hline $\begin{array}{l}\text { Drop } \\
\text { test }\end{array}$ & Pool boiling & $\begin{array}{l}\mathrm{N}_{2}, \\
\mathrm{R} 113\end{array}$ & No & Yes & Saturated & $\begin{array}{l}\text { Surface super- } \\
\text { heat less in } \\
g\end{array}$ & $\begin{array}{l}\text { Transient } \\
\text { results; } \\
\text { g fields high } \\
\text { (approx. } 0.004 \text { ) }\end{array}$ & $\begin{array}{l}\text { Oker and Merte } \\
\text { (1973) }\end{array}$ \\
\hline $\begin{array}{l}\text { Air- } \\
\text { craft }\end{array}$ & $\begin{array}{l}\text { Flow regimes } \\
\text { and pressure } \\
\text { drop }\end{array}$ & $\begin{array}{l}\text { Air and } \\
\text { water }\end{array}$ & Yes & None & $N / A$ & $\begin{array}{l}\text { g-level influ- } \\
\text { ences flow } \\
\text { regime, which } \\
\text { influences } \Delta P\end{array}$ & $\begin{array}{l}\text { Good basis } \\
\text { for future } \\
\text { work }\end{array}$ & $\begin{array}{l}\text { Heppner, King, and } \\
\text { Littles (1975) }\end{array}$ \\
\hline
\end{tabular}


IABLE 4.2. (contd)

\begin{tabular}{|c|c|c|c|c|c|c|c|c|}
\hline Iype & Investigated & Eluids & Elow & - Iransfer & Liquid State & Conclusions & Comnent & Reference. \\
\hline $\begin{array}{l}\text { Air- } \\
\text { craft }\end{array}$ & $\begin{array}{l}\text { Flow regimes } \\
\text { in condensa- } \\
\text { tion }\end{array}$ & $R-12$ & Yes & Qualitative & $\begin{array}{l}\text { Superheated/ } \\
\text { saturated }\end{array}$ & $\begin{array}{l}\text { Baker chart } \\
\text { valid; no } \\
\text { reduction in } \\
\text { heat transfer } \\
\text { with } \mathrm{g}\end{array}$ & $\begin{array}{l}\text { Not directly } \\
\text { useful }\end{array}$ & $\begin{array}{l}\text { Willians (1974) } \\
\text { Keshock et al. } \\
\text { (1974) } \\
\text { williams, Keshock, } \\
\text { and Wiggins (1973) }\end{array}$ \\
\hline $\begin{array}{l}\text { Air- } \\
\text { craft }\end{array}$ & $\begin{array}{l}\text { Pressure } \\
\text { drop and } \\
\text { phase } \\
\text { velocities } \\
\text { in conden- } \\
\text { sation }\end{array}$ & Mercury & Yes & Yes & $\begin{array}{l}\text { Superheated/ } \\
\text { dropwise } \\
\text { condensation }\end{array}$ & $\begin{array}{l}\text { Little difference } \\
\text { between } 0-g \text { and } \\
1-g \text { data }\end{array}$ & $\begin{array}{l}\text { Not directly } \\
\text { useful }\end{array}$ & $\begin{array}{l}\text { Albers and Macosko } \\
(1965) \\
\text { Namkoong et al. } \\
(1967)\end{array}$ \\
\hline Rocket & $\begin{array}{l}\text { Yoid (i.e., } \\
\text { bubble) } \\
\text { migration } \\
\text { in molten } \\
\text { glass }\end{array}$ & $\begin{array}{l}\text { Sodiun } \\
\text { borate } \\
\text { glass }\end{array}$ & No & $\begin{array}{l}\text { Not } \\
\text { exaw ined }\end{array}$ & $N / A$ & $\begin{array}{l}\text { Bubbles igrate } \\
\text { against thermal } \\
\text { gradient at } \mathrm{g}\end{array}$ & $\begin{array}{l}\text { Not directly } \\
\text { useful }\end{array}$ & $\begin{array}{l}\text { Wilcox et al. } \\
(1981)\end{array}$ \\
\hline
\end{tabular}

a few two-phase flow experiments are actually in progress, and descriptions follow. These involve mainly universities, al though several study contracts have been arranged with industry.

Regarding future fluids experiments, most activities for the shuttle and the space station deal with cryogen storage (NASA 1985). Very little from those studies will be applicable to two-phase turbulent alkali-metal flow and heat transfer.

\subsubsection{University Activities}

Several universities (e.g., the University of Michigan) have small drop towers that have seen use for thesis work (Oker and Merte 1973). NASA has contracts with three universities to perform a series of tests, spanning 
facilities from drop towers to Spacelab. The University of Houston (a) is responsible for adiabatic pressure drop/flow regime delineation in reduced gravity as well as determining "burnout" heat fluxes. The NASA mandate for the University of Michigan ${ }^{(b)}$ is to examine forced convection boiling, including heat transfer coefficients from flat surfaces and interfacial evaporation/condensation rates. Meanwhile, at Texas A\&M University forcedflow condensation and heat transfer are being examined. (c) At their current stage of development, these experiments will be utilizing drop towers and aircraft this year, with shuttle experiments to follow sometime in the future.

Less formal arrangements also exist between NASA and some other universities. Thus, the universities are able to use facilities such as the LeRC 2.2-s drop tower and Learjet for thesis work.

It appears that much of this work could prove to be of major import to the space reactor program. All three university groups are interested in defining the basic physical phenomena associated with reduced-gravity twophase flow and heat transfer. As such, no specific application has influenced the nature of the proposed activities. Perhaps inputs from MMW programs and organizations (including funds) could sway the experiments to represent incore boiling mechanisms.

\subsubsection{Industry Activities}

Industry has been reluctant, in spite of its expressed interest, to initiate reduced-gravity experiments on its own. To stimulate industry participation in the shuttle and space station experimental programs, NASA last year set up several technology centers and offered seed money to begin experimental programs. The response was gratifying, and there are high hopes that industry will become an active partner in future endeavors.

\footnotetext{
(a) Dukler, A. E. 1985. Personal communication, May 16 and November 21, 1985, University of Houston.

(b) Merte, H. Jr. 1985. Personal communication, May 17 and November 22, 1985, University of Michigan.

(c) Best, F. R. 1986. Personal communication, February 3, 1986, Texas A\&M
University.
} 
The extent, timing, and specificity of industrial experiments remain to be determined. Until more information becomes available, one will have to reserve judgment on the relevance of industry efforts to the task described here. But most of the papers presented at a recent space research workshop (NASA 1985) are of only marginal interest because they dealt with cryogen storage and boil off problems. Also, these papers generally dealt with reducedgravity issues in a rudimentary manner, so it appears that considerable time will elapse before realistically designed industrial experiments will be able to take place.

One fluid experiment will have a decided bearing on future two-phase activities. The NASA JSC has recently (1985) awarded a contract to the General Dynamics Convair Division to engineer a shuttle mid-deck experiment (Schuster 1985). The objective is to obtain basic two-phase flow data; initial experiments will be adiabatic, using an air/water mixture. This experiment may be performed in cooperation with one of the aforementioned universities. It is anticipated that the experiment, which will take about $1-1 / 2 h$, will be flown aboard the shuttle in 1988 (Schuster 1985).

The reason for optimism on this particular experiment is that General Dynamics has extensive expertise in such research, having recently completed a detailed design of a similar experiment (Bradshaw and King 1977). That design, and the accompanying test plan, had features that could readily be incorporated into any future experiments.

\subsection{PROPOSED TWO-PHASE REDUCED-GRAVITY EXPERIMENTS}

The broad objective of this experimental program is to obtain sufficient data to characterize two-phase alkali-metal flow and heat transfer in a reducedgravity environment. While this goal is clear enough, its attainment is anything but simple. 


\subsubsection{Approach}

The twin issues posed by experimental facility limitations and the difficulties inherent in working with alkali metals must be squarely faced by any realistic test program. Thus, the only viable approach is to perform, to the maximum possible extent, experiments with innocuous fluids such as air, water, and Freon in place of the alkali metals. Only if the desired data were to be seriously flawed by replacement fluids will alkali metals themselves become the working fluids. At this time the feeling is that perhaps alkali metals might be acceptable for use in drop towers and the KC-135 aircraft, (a) but would present an unacceptable hazard in any other reduced-gravity test facilities. (b)

Doing the experiments in a piecemeal manner ensures safety, timeliness, and reduced costs. But there is a negative side to such a scheme: the reliability of the data so obtained is in question. That is, there is no assurance that the data obtained with various fluids can ever be assembled to represent an alkali metal. Yet this approach appears to have been validated in rudimentary fashion (Fraas 1964; MacPherson and Fraas 1965; Yarosh 1965) and was recently employed successfully in designing the Fast Flux Test Facility (FFTF) at Hanford. (c) Note that the alkali metal coolant in the FFTF does not undergo a phase change. Plus the complication of zero gravity further strains possible analogies among different fluids. Still, the approach has merit, and there is the hope that, by exercising care and judgment, one can achieve results valid for alkali metals. Arguments substantiating this claim are provided below.

Boiling phenomena associated with low Prandtl number fluids (e.g., alkali metals) differ substantially from those of higher-Prandtl fluids (e.g., water,

(a) Williams, R. 1986. Personal communication, March 6, 1986, NASA Johnson Space Center, Houston, Texas.

(b) Vernon, R. W. 1985. Personal communication, November 21, 1985, NASA Lewis Research Center, Cleveland, Ohio.

(c) Bates, J. M. 1985. Personal communication, January 15, 1986, Pacific Northwest Laboratory, Richland, Washington. 
ammonia, Freons). Heat transport is by different mechanisms, bubble formation and fluid agitation evince different characteristics, and interaction with the container surface (i.e., wettability) is a potential problem. However, there is some overlap in the properties of high-and low-Prandtl-number fluids. For example, the physical properties of water at $0.2 \mathrm{MPa}$ and in the 300 to $400^{\circ} \mathrm{K}$ range are quite similar to the properties of potassium in the 825 to $1150^{\circ} \mathrm{K}$ range.

The data in Table 4.3 provide a comparison of the relevant properties of potassium with various fluids being considered for testing in its place. Potassium properties are given at a temperature and pressure that might be representative for a boiling alkali metal nuclear reactor; the properties of the other fluids were selected for expansion ratios (i.e., $\rho_{\ell} / \rho_{V}$ ) equal to that of the potassium. It is felt that this matching best ensures similarity in boiling mechanisms, although other measures of similitude (such as the viscosity ratio, $\left.\nu_{v} / \nu_{\ell}\right)$, may be equally important in certain flow regimes at high-Reynolds number (Heppner, King, and Littles 1975).

From Table 4.3, it is clearly evident that several fluids closely resemble the potassium, with water and ammonia yielding the best match. Freon-11 is somewhat less akin to potassium, but offers the advantage of a low-temperature and low-pressure boiling point. Methanol fits between the extremes of the other fluids.

Several nondimensional numbers, thought to be important in 0 -g work, have been calculated from the data in Table 4.3 and are given in Tables 4.4 and 4.5. The values in Table 4.4 are based on a constant $G=1000 \mathrm{~kg} / \mathrm{m}^{2} \mathrm{~s}$, while dynamic similitude, with constant Reynolds numbers, results in the values in Table 4.5. From these data, it is concluded that a partial similitude can always be achieved, but never a total one. Bomelburg (1968) provides an excellent discussion of this topic and identifies some of the pitfalls in using analogies. He has reservations regarding the use of water in place of alkali metals, especially for heat-transfer experiments (p. 65). Recent European experiments with adiabatic two-phase alkali-metal flow support the 
validity of using water for pressure-drop correlations (Kottowski et al. 1976). A different conclusion is reached from a Russian experiment (Zeigarnick and Litvinov 1980), indicating that two-phase alkali-metal pressure drop is greater for adiabatic than nonadiabatic conditions. Like so many alkali-metal

\section{TABLE 4.3. Candidate Fluid Properties}

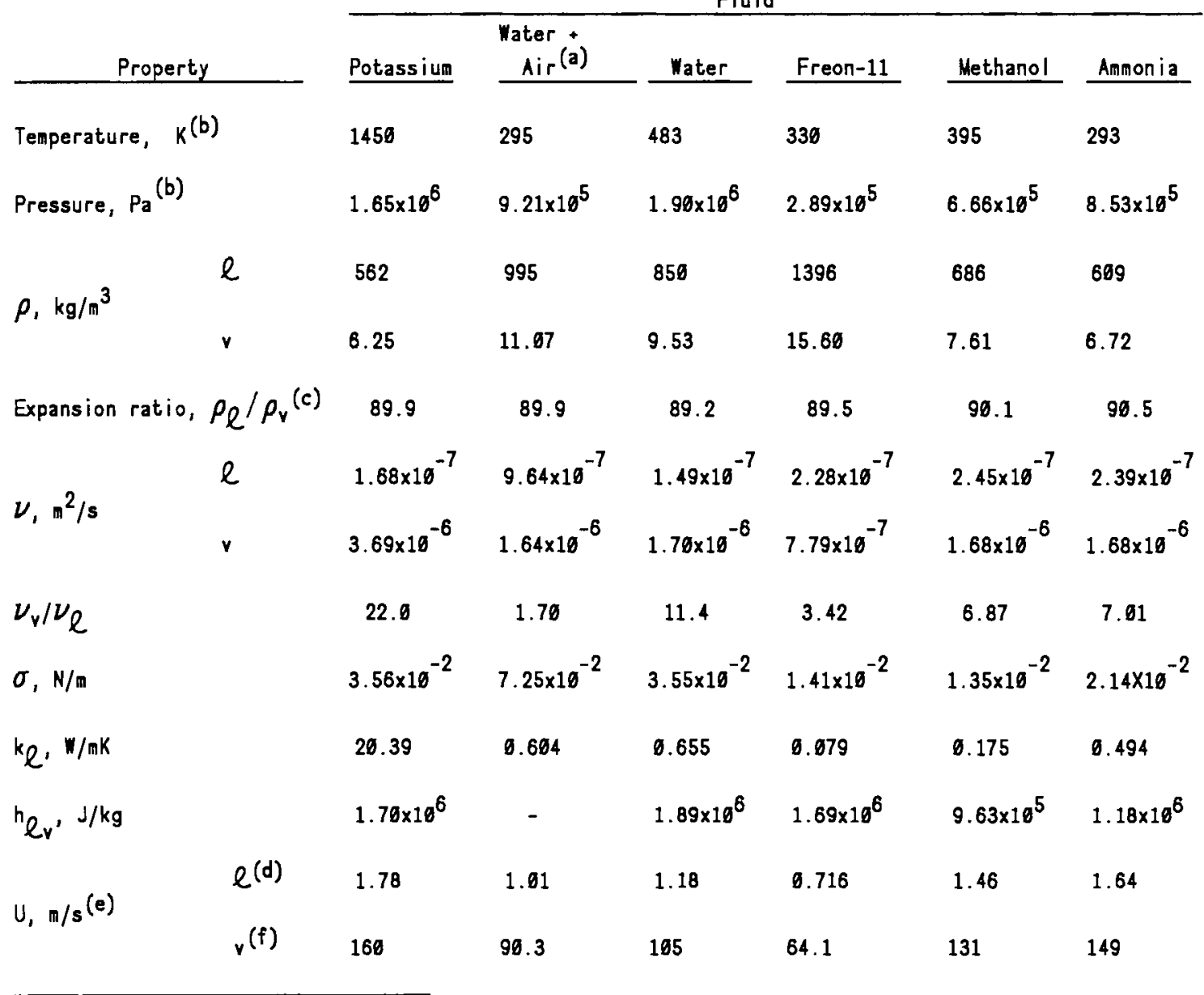

\footnotetext{
(a) For room temperature adiabatic experiment

(b) Saturated conditions.

(c) Probably most important parameter for similitude. Set equal to potassium value.

(d) Assumes $x=0.0$.

(e) At $G=1000 \mathrm{~kg} / \mathrm{m}^{2} \mathrm{~s}$ (maximum) in a $0.02-\mathrm{m}$ ID tube.

(f) Assumes $x=1.00$.
} 
TABLE 4.4. Comparison of Candidate Fluids at $G=1000$

Fluid

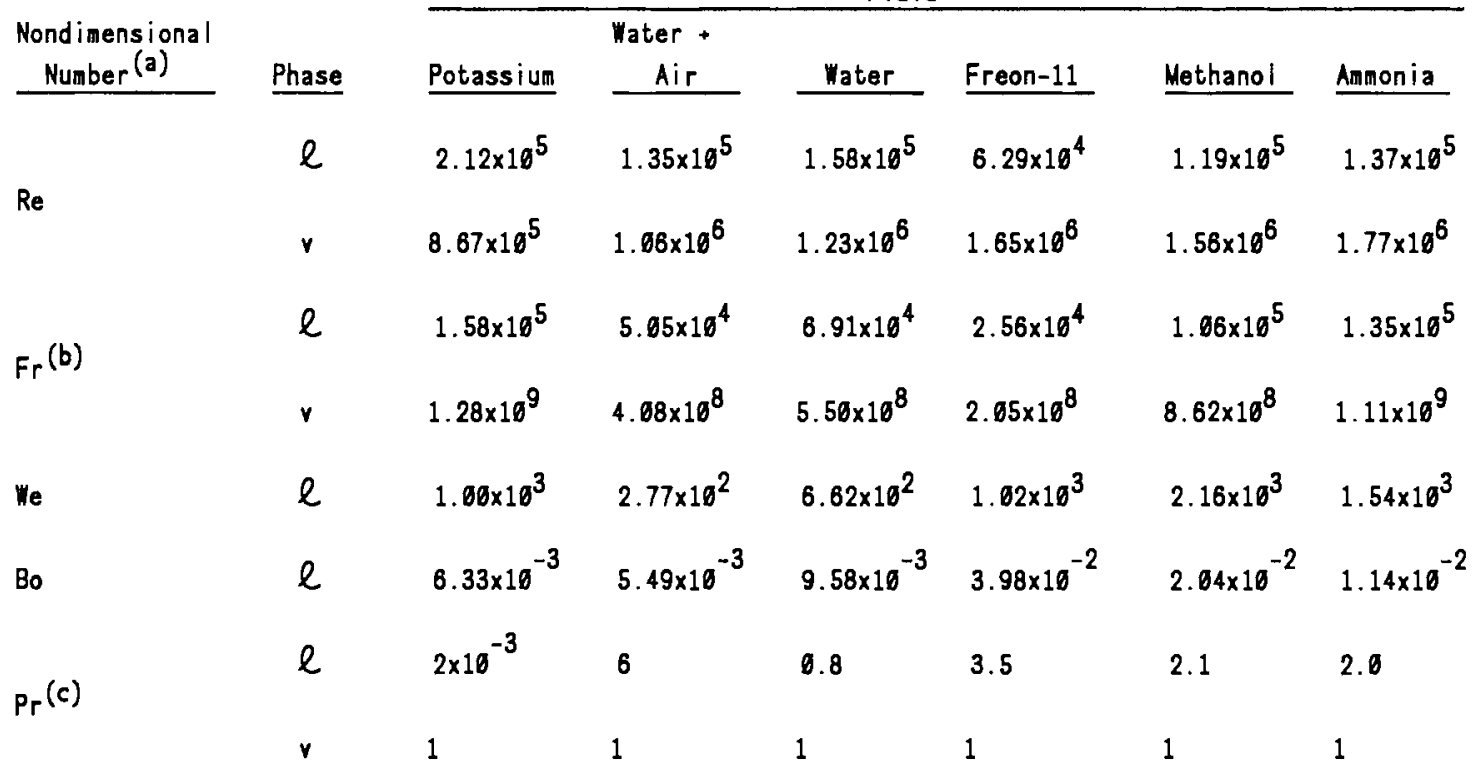

(a) Based on data jn Table 4.3 .
(b) Assumes g $10^{-3}$ (c) Approximate.

experiments, it also was performed in a very small-diameter (5-mm I.D.) tube, so extension to large-diameter flows remains questionable.

One further issue remains to be discussed. Liquid-metal flow development is much more gradual than is the case with a high-Prandtl fluid such as water (Kays 1966). Now both the test section and actual space hardware (such as the reactor, heat exchangers and piping) will necessarily have low length/diameter ratios. Thus, flow development will exert a significant influence on the performance ( $\Delta P$ and heat transfer) of this equipment. Yet the developing flow and velocity profiles in the experimental device will tend to mask, or modify, the measured parameters and effects. Extrapolating what is observed with water under $0-g$ conditions to a liquid metal with a very different flow development length requirement may prove difficult. 
IABLE 4.5. Comparison of Candidate Fluids at constant Re

\begin{tabular}{|c|c|c|c|c|c|c|c|}
\hline \multirow[b]{2}{*}{$\begin{array}{l}\text { Nond imens ional } \\
\text { Number (a) }\end{array}$} & \multirow[b]{2}{*}{ Phase } & \multicolumn{6}{|c|}{ Fluid } \\
\hline & & Potassium & $\begin{array}{l}\text { Water + } \\
\text { Air }\end{array}$ & Mater & Ereon-11 & Methanol & Ammonia \\
\hline \multirow{2}{*}{$\operatorname{Re}$} & $\ell$ & $2.12 \times 10^{5}$ & $2.12 \times 10^{5}$ & $2.12 \times 10^{5}$ & $2,12 \times 10^{5}$ & $2.12 \times 10^{5}$ & $2.12 \times 10^{5}$ \\
\hline & $v$ & $8.67 \times 10^{5}$ & $8.67 \times 10^{5}$ & $8.67 \times 10^{5}$ & $8.67 \times 10^{5}$ & $8.67 \times 10^{5}$ & $8.67 \times 10^{5}$ \\
\hline \multirow{2}{*}{$\mathrm{Fr}^{(b)}$} & $\ell$ & $1.58 \times 10^{5}$ & $5.24 \times 10^{6}$ & $1.26 \times 10^{5}$ & $2.92 \times 10^{5}$ & $3.38 \times 10^{5}$ & 3. $23 \times 10^{5}$ \\
\hline & $v$ & $1.28 \times 10^{9}$ & $2.53 \times 10^{8}$ & $2.72 \times 10^{8}$ & $5.71 \times 10^{7}$ & $2.86 \times 10^{8}$ & $2.64 \times 10^{8}$ \\
\hline We & $\ell$ & $1.00 \times 10^{3}$ & $2.88 \times 10^{4}$ & $1.20 \times 10^{3}$ & $1.16 \times 10^{4}$ & $6.87 \times 10^{3}$ & $3.67 \times 10^{3}$ \\
\hline Bo & $\ell$ & $6.33 \times 10^{-3}$ & $5.50 \times 10^{-3}$ & $9.54 \times 10^{-3}$ & $3.98 \times 10^{-2}$ & $2.83 \times 10^{-2}$ & $1.14 \times 10^{-2}$ \\
\hline \multirow{2}{*}{$\mathrm{Pe}^{(c)}$} & $\ell$ & $4.24 \times 10^{2}$ & $1.27 \times 10^{6}$ & $1.78 \times 10^{5}$ & $7.42 \times 10^{5}$ & $4.45 \times 10^{5}$ & $4.24 \times 10^{5}$ \\
\hline & $r$ & $1.02 \times 10^{6}$ & $6.16 \times 10^{5}$ & $1.04 \times 10^{6}$ & $6.85 \times 10^{5}$ & $3.29 \times 10^{5}$ & $7.46 \times 10^{5}$ \\
\hline \multirow{2}{*}{$U, \mathrm{~m} / \mathrm{s}$} & $\ell(d)$ & 1.78 & 10.2 & 1.59 & 2.42 & 2.60 & 2.54 \\
\hline & $v^{(e)}$ & 160 & 71.1 & 73.8 & 33.8 & 73.6 & 72.7 \\
\hline
\end{tabular}

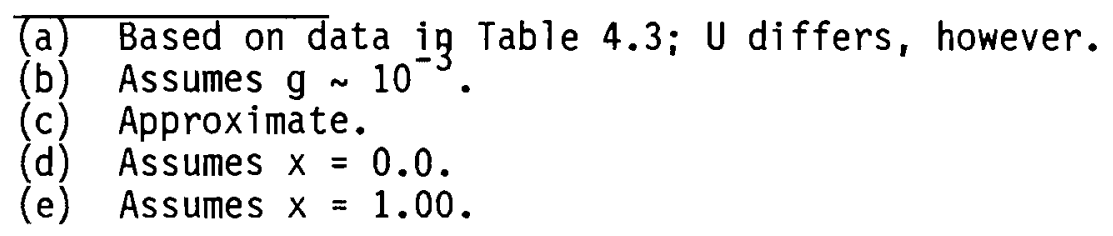

In spite of all the caveats noted, it is felt that use of alternate fluids in place of alkali metals is justified. Every attempt will be made to verify that the experiments with these fluids will truly represent alkali-metal behavior.

Another aspect of the proposed test series is one of partitioning. This entails doing the experiments at various times and facilities, and examining phenomena such as pressure drop and heat transfer in separate experiments. Given the large variation in facility features (see Table 4.1), several test 
packages will have to be constructed because no single package will be satisfactory for all. In fact, each facility employed will probably require a unique test package, which imposes an additional burden in terms of time and effort expended to accomplish the task. As before, the reason for having a multiplicity of tests, fluids, test packages, and other factors is one of practicality. The goal is to obtain the data as expeditiously and costeffectively as possible.

As was mentioned, one partitioning envisioned is the separation of adiabatic and heat transfer tests. In this manner, the adiabatic experiments will yield data on pressure drop and flow regimes--data that are much easier to secure without trying for simultaneous heat-transfer measurements. Similarly, the heat-transfer experiments will concentrate on the heat-transfer mechanisms with only perfunctory pressure-drop measurements. The overall benefits anticipated are more accurate data obtained in the most efficient way.

In conclusion, the approach taken here is fairly typical of experiments that delve into complex phenomena. Fluid-flow and heat-transfer effects in reduced gravity can best be elucidated via narrowly scoped experiments that assess only a few parameters. The methodology is succinctly portrayed in Table 4.6, which, while it has an element of subjectivity, still quantifies the issues and arguments raised up. In sum, the "partitioned" approach is more realistic than an all-encompassing "global" approach and achieves its objective in a sort of evolutionary manner. Great flexibility is a side benefit.

\subsection{2 objectives}

Each experiment (e.g., pressure drop/flow regime, heat transfer, maximum heat flux) will consist of a series of tests whose objective is to "map" the parameters of interest over a broad range of conditions. The variables to be measured will consist of temperatures, pressures, mass flow rates, velocities, and void fractions; flow regimes will be determined from film.

Because all earth-based reduced-gravity test facilities are able to provide a reduced-gravity of only short duration, rapid instrument response and high data-transfer rates are important. Accurate and reliable data must be ensured, 
so the measurements must be copious over the short test time and must provide evidence that steady-state conditions prevailed during some portion of the test. Data scatter must be $\leq 20 \%$ to be acceptable. These objectives can be met with state-of-the-art instrumentation and data acquisition systems.

IABLE 4.6. Test Approach Options and Ratings

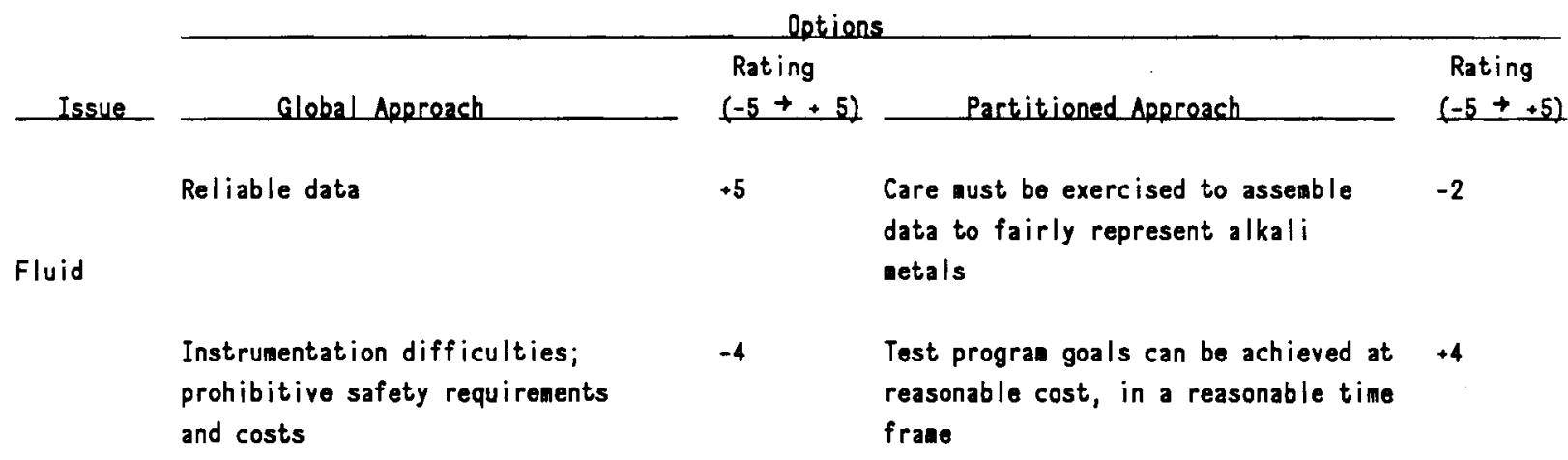

Space-based laboratory facility would provide the most reliable data

Facility

No such facility will exist, until the construction of the space station in the mid-1990s
$+3$ Require more tests, several test

$-2$ packages; less reliable data is obtained

Efficient use of existing facilities
Most direct approach; straightforward +1 Experiment

Difficult to measure all parameters -4 simultaneously
Complex

$-1$

Parameter-specific; provides valid $\quad+4$ correlations 
The literature is replete with two-phase pressure-drop, heat-transfer, and critical-heat-flux correlations (for example, see Hetsroni 1982; Hsu and Graham 1976; Bradshaw and King 1977). As the test data become available, existing correlations will be examined and, if feasible, adapted to represent reducedgravity conditions. Alternatively, new correlations will be developed as needed. It is impossible to predict what form these may take, as the experiments are the only valid source for the correlations. If one were able to derive such correlations from first principles, the need for experiments would be obviated. But two-phase flows are not fully understood even in normal gravity, so reduced-gravity mechanisms and trends can be postulated but not proven theoretically.

\subsubsection{General Plans}

Although all the details and ramifications of a reduced-gravity two-phase experimental program have not been determined, still the main tasks can be broadly scoped. MMW activities must be coordinated with NASA and researchers (e.g., University of Michigan, University of Houston, Texas A\&M University) regarding ongoing and $\mathrm{planned}$ reduced-gravity experiments. The intent here is to avoid duplication and perhaps to exert some influence on the nature of the experiments performed for non-MMW projects.

A parallel task in securing information should examine the reactor concepts being proposed that employ two-phase alkali metals. This will permit selection of the alkali metals and parameter ranges for study.

Subsequently, a number of choices must be made. These include determination of the parameters to be measured in the experiments; fluids to be tested, selection of instruments and data acquisition systems; and finally, design of a control scheme that will require a minimum of human intervention. The options available are strongly circumscribed by the availability and features of the reduced-gravity facilities. More than likely, the selection process will be an iterative one as facility constraints set the experiment bounds, while data needs favor certain facilities over others. 
Once the above task is complete, an experimental package to house the experiment and ancillary equipment can be designed and constructed. This sets the stage for the writing of a detailed test plan, and its execution. As the test series progresses the data obtained will be evaluated in terms of validity and applicability to MMW needs. If any deficiencies are observed, suitable corrective action will be taken. Given the exploratory nature of the experiments and the broad scope of this project, flexibility in execution of the tests is an absolute must. These same tasks are illustrated in flow chart format in Figure 4.2. Some indication of the scheduling and timing of individual tasks is also provided. Proper scheduling is critical, for two reasons :

1. to ensure availability of test facilities

2. to ensure timely availability of data and correlations to the code development effort.

As noted earlier, it is hoped that all, or most, reduced-gravity experiments can be done with nonhazardous fluids and still provide data and correlations applicable to alkali metals. Hazardous materials are to be avoided in shuttle flights. As data become available and evaluation indicates the need for reduced-gravity alkali-metal experiments, serious consideration will have to be given to what constitutes an acceptable experimental package. Perhaps a free-flying module, to be launched from the shuttle, could be designed with suitable safety equipment to permit alkali-metal use. No doubt this will prove an expensive option, but it may be necessary so as not to compromise an even more expensive MMW design and mission.

\subsubsection{Conclusions and Recommendations}

The experimental effort about to be embarked on will be a demanding one. Great care will have to be exercised in both planning and execution of the requisite two-phase experiments. The time constraints are fairly severe, and much needs to be done in a relatively short time frame. This holds especially for any two-phase alkali-metal experiments that may have to be done in a reduced-gravity environment. 
TIME

FRAME

$\overline{=}$

1987

1988

1989

1990

1991

1992

\section{TWO-PHASE REDUCED-g} EXPERIMENTS

\section{PLANS}

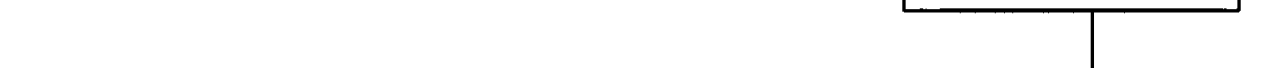

\section{DROP TOWER AIRCRAFT}

$\mathrm{H}_{2} \mathrm{O}, \mathrm{NH}_{3}$, FREON, $\mathrm{AIR} / \mathrm{H}_{2} \mathrm{O}$

ALKALI METAL

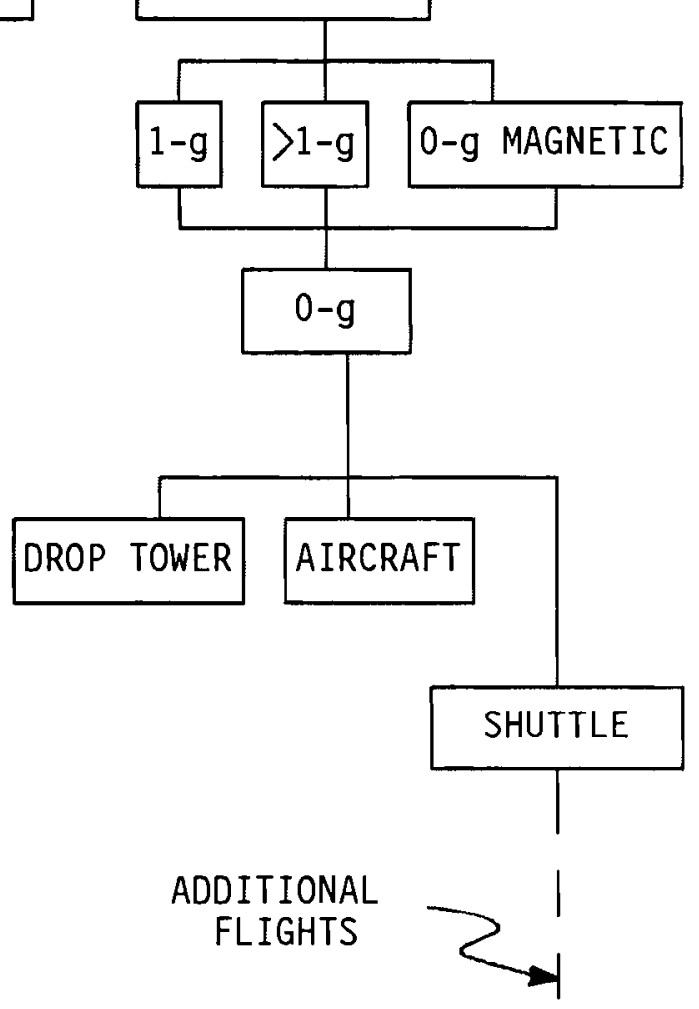

FIGURE 4.2. Two-Phase Reduced-Gravity Experimental Task Flow 
The recommended approach to this experimental task is to use substitute fluids in place of the alkali metals and to use ground-based facilities to the maximum extent. A separate document for each experiment should be generated, incorporating a detailed account of the specific procedure, equipment, test plan, and other features. Such a document has already been written for the pressure-drop/flow-regime experiment, which is to be performed in drop towers with an air/water mixture. Other documents will be forthcoming as needed. 


\subsection{ALKALI METAL EXPERIMENTS IN GRAVITY FIELDS}

The history of liquid metal (including non-alkali metals like mercury) experiments is a short one, and essentially parallels the invention and development of nuclear reactors. Although reactors have generally utilized common fluids such as water, the advantages of liquid metals in this application were quickly appreciated. These advantages relate mainly to more efficient heat transport--leading to reduced $\Delta$ Ts and smaller heat exchangers. Added benefits are potentially lower pump power needs (e.g., with lithium) and, if boiling were selected, much lower boiling pressures than with water (again reducing equipment-mass requirements). Smaller, lighter reactors are most beneficial to military propulsion (e.g., surface vessels, submarines, and aircraft) and space applications, where weight and efficiency become overriding issues.

From the beginning, two research paths were pursued (Jackson et al. 1955). One approach was to use a single-phase liquid metal, and this only in the reactor system, with conventional (steam) use on the turbine side (Murray 1961; Jackson et al. 1955). This approach has been explored the most and led to the construction of the Experimental Breeder Reactor (EBR II) and the FFTF. The latter is still operating at Hanford. Before those facilities could become operational, much research work--spanning items such as liquidmetal thermophysical properties, heat-transfer coefficients, and materials compatibility--had to be completed.

The second, more daring, approach envisioned the boiling of a liquid/alkali metal and its subsequent use directly as the working fluid in a heat engine. Various designs such as SNAP-8, which was to use mercury in a Rankine turbine (Poppendiek and Sabin 1975, p. 213), to a potassium Rankine turbine (p. 222) were partially realized. A viable system was never constructed, as both funding and advanced space missions were severely curtailed. Thus, most of the work in this area ceased in the early 1970s, and much of it is inadequately documented. Although the current need for an advanced space reactor is an outgrowth of these past efforts, it can benefit from past experience only to 
a limited extent. One reason, the lack of solid data, has been mentioned. Another is that future space reactors are projected to produce much greater amounts of power, at much higher temperatures and flow rates, than those conceived heretofore. This places enormous demands on the designer of a space nuclear power system in terms of both analytical and experimental capabilities.

Nevertheless, past research is of some interest here and will be covered briefly. Only the main experiments, selected for their relevance to current needs or because of their ongoing nature, will be touched upon. No attempt will be made to replicate the information in summary work by authors such as Dwyer (1976); Dwyer (1973); Poppendiek and Sabin (1975); Tong (1965); Jackson et al. (1955); or the bibliography maintained in the recent past by Oak Ridge National Laboratory (Michelson et al. 1983). Liquid-metal experiments demand sophisticated facilities, so such experiments have taken place at relatively few facilities. Because the facilities have served to limit experiments in terms of temperature, types of fluids used, and other parameters, it is logical for the discussion to be categorized by facilities. Only two-phase alkalimetal work will be considered; transient boiling, such as encountered in a loss-of-coolant accident (LOCA) at a reactor, is only of marginal interest and will not be covered.

\subsection{PAST TWO-PHASE ALKALI-METAL EXPERIMENTS}

Past experiments have been conducted at four major laboratories and by several other organizations.

\subsubsection{Dak Ridge National Laboratory (ORNL)}

In the mid-1960s, ORNL was involved in building and testing components for the Medium Power Reactor Experiment (MPRE). Several sizes of boilingpotassium test loops were built (MacPherson and Fraas 1965), and some preliminary tests were run. The difficulty of working with potassium led to a similarity analysis of other fluids; water was selected for possessing properties similar to those of potassium, in certain temperature ranges. This prompted extensive use of water, which aided experimenters in the design 
of the potassium test loops. Not much documentation is available on these potassium boiling tests (MacPherson and Fraas 1965; Yarosh 1965).

The larger potassium loop was later converted to another purpose, the study of transient sodium boiling in a LOCA. (a) This facility still exists at ORNL, but would require considerable refurbishment and updating for any future boiling alkali-metal tests. Oak Ridge has been, and continues to be, much involved in materials and materials compatibility testing. Tests consist of small vacuum furnaces in which refractory alloy samples are immersed in various alkali metals, often for thousands of hours.

In the past, ORNL was also involved in measurements of the thermophysical properties of alkali metals. This laboratory continues to be a supplier of refined alkali metals to experimenters (e.g., Los Alamos National Laboratory).

\subsubsection{Los Alamos National Laboratory (LANL)}

In recent years LANL has been a strong proponent and developer of liquid metal heat pipes, especially for application as high-temperature space radiators. Much of the LANL work has been published over the past few years in the Intersociety Energy Conversion Engineering Conference (IECEC) proceedings. Although heat pipes do require the working fluid to undergo phase changes, the evaporation process taking place in a heat pipe does not involve true boiling. Furthermore, the working fluid in a heat pipe experiences conditions radically different from those it would encounter in a boiling metal reactor. As a result, only a small portion of the data generated from heat pipe experiments is applicable to a boiling situation.

\subsubsection{Argenne National Laboratory (ANL)}

Argonne has an extensive background in alkali metals. A cursory appraisal $^{(b)}$ suggests that the bulk of the experience, like ORNL's, is related

(a) Wantland, J. 1985. Personal communication, April 3, 1985. ORNL, Oak Ridge, Tennessee.

(b) Singer, R. M. 1985. Personal communication, April 2, 1985. ANL, Argonne, Illinois. 
either to transient boiling simulating a LOCA or to materials studies. Again, the data obtained can provide but few answers to the design questions posed by a MMW reactor.

\subsubsection{Hanford Engineering Development Laboratory (HEDL)}

The experience at HEDL parallels that of the other laboratories involved in the development of nuclear reactors. Most of the tests were done with single-phase alkali metals. Several of the test loops still exist and could be adapted for two-phase work. (a) However, considerable modernization of the control, instrumentation, and data acquisition systems would be necessary for such a task.

\section{1 .5 Qthers}

Many other organizations, such as Columbia University and Brookhaven National Laboratory (Chen and Kalish 1970), have performed some work with the alkali metals. These organizations are generally no longer working with alkali metals. Rocketdyne is one company that still maintains and operates a singlephase test facility. (b) This is a fairly modern test complex and probably could be readily modified for two-phase experiments. A comprehensive literature search $^{(c)}$ has disclosed that over the past decade essentially no new information on steady-state alkali-metal boiling has been generated in the U.S. In contrast, some work in this area continues to be performed in Europe (Kottowski et al. 1976) and the U.S.S.R. (Zeigarnick and Litvinov 1980). The work provides some interesting insights into alkali-metal boiling phenomena and the difficulties associated with obtaining valid measurements of the same.

(a) Thorne, W. L. 1985. Personal communication during facilities tour, June 3, 1985. Hanford Engineering Design Laboratory (HEDL). Richland, Washington.

(b) Gillies, B. B. 1985. Presentation at HEDL. December 19, 1985. Rocketdyne Division, Rockwell International, Canoga Park, California.

(c) Carter, N. G. 1985. Personal communication on search of energy data base for documents on sodium, potassium, and liquid metal boiling, covering the decade 1975 to 1984. Pacific Northwest Laboratory Library, Richland, Washington. March 4, 1985. 


\subsubsection{General Electric Company (GE)}

Under NASA contracts, GE performed a number of boiling alkali-metal experiments in the 1960 s and early 1970s. These culminated in a large, hightemperature experiment meant to explore the use of potassium as a working fluid in a Rankine-cycle heat engine. Because of their relevance to the current MMW effort, the GE experiments merit additional discussion.

The objective of the GE tests, then as now, was the development of an efficient, low-mass, space power system in the MMW size range. The specific tasks in this effort consisted of designing and constructing a facility capable of testing full-scale Rankine cycle components and of operating the facility (Wettach 1966).

A 400-kW-th test rig was constructed in the refractory-metal tantalum alloy T-111 ( $\mathrm{Ta}-8 \mathrm{~W}-2 \mathrm{Hf})$. Three separate fluid loops comprised the heat exchanger portion: a single phase lithium heating loop; a two-phase potassium working-fluid loop; and a potassium/sodium heat-rejection loop (Amos 1975; Wettach 1966). Because the T-111 oxidizes readily, the loops were housed in a large vacuum chamber.

The test rig was initially operated for $100 \mathrm{~h}$ to demonstrate design point operation. Potassium conditions then were representative of those envisioned for an advanced Rankine cycle turbine: $1422^{\circ} \mathrm{K}$ boiler exit temperature, with $40^{\circ} \mathrm{K}$ of superheat (Amos 1975). In this mode, the test equipment was calibrated, and various problems that surfaced were solved.

The follow-on tests of the potassium boiler, heated with the liquid lithium and rejecting heat via a condenser to liquid NaK-78, are of greatest interest. The final report (Deane 1975) presents data on two-phase pressure drop, heat transfer coefficients, and critical heat fluxes. The range of potassium conditions at the boiler exit spanned wet vapor at $50 \%$ quality to dry vapor with $167^{\circ} \mathrm{K}$ of superheat. Condenser inlet conditions were also varied, from 45 to $99 \%$ quality and from 867 to $1144^{\circ} \mathrm{K}$ saturation temperatures. 
The data show a fair amount of scatter, which was attributed to the type and size (i.e., component evaluation) of the test rig used. Although trends generally seem to follow those predicted by commonly used correlations, actual discrepancies between test and correlations are large (Deane 1975). It bears noting that the potassium boiler augmented heat transfer by means of helical vanes and coils. The augmentation was accounted for with a correction factor of (local acceleration) ${ }^{1 / 4}$. At any rate, this test rig demonstrated the feasibility of using a boiling alkali-metal working fluid in a space reactor. But it did not provide sufficient data, at high enough accuracy, to be the final word on the topic. As a benchmark experiment, the GE/NASA work can serve as an excellent starting point for future tests.

\subsubsection{Conclusions and Recommendations}

Although research on two-phase liquid/alkali metal has received considerable attention in the past, no definitive data or correlations are available. The common thread in the books and papers that have surveyed the field is negative. Dwyer (1976) comments on the developing nature of this field and offers this as an explanation for conflicting experimental results and lack of theoretical models. Bomelburg (1976) reports that much of the twophase experimental data is suspect because of various deficiencies in conducting the experiments. Kottowski et al. (1976) mention that discrepancies exist between theoretical predictions and known experimental results. They express uncertainty regarding the applicability of friction-factor correlations for two-phase flow in boiling water to alkali metals, even while recommending simulation experiments with water for purposes of code development. Chen and Kalish (1970), Zeigarnick and Litvinov (1980), and No and Kazimi (1982) make similar critical observations. The experiments recently performed by Zeigarnick and Litvinov (1980) were intended to address some of the issues raised by earlier work. A brief summary of past work is given in Table 5.1. 
TABLE 5.1. Survey of Representative Boiling Liquid Metal Tests

\begin{tabular}{|c|c|c|c|}
\hline Iype of Test & Purpose & $\begin{array}{l}\text { Organization } \\
\text { Performing Test }\end{array}$ & Comment \\
\hline $\begin{array}{l}\text { Pool boiling/ } \\
\text { transient }\end{array}$ & LMFBR Safety & $\begin{array}{l}\text { Oak Ridge Nat. Lab., } \\
\text { Argonne, Brookhaven }\end{array}$ & $\begin{array}{l}\text { Relevance to steady-state } \\
\text { forced-flow boiling is remote }\end{array}$ \\
\hline $\begin{array}{l}\text { Maximum heat } \\
\text { flux }\end{array}$ & $\begin{array}{l}\text { Heat pipe } \\
\text { development }\end{array}$ & Los Alamos Nat. Lab. & $\begin{array}{l}\text { Only some of the problems } \\
\text { encountered in heat pipes } \\
\text { (e.g., wettability) are of } \\
\text { interest. }\end{array}$ \\
\hline $\begin{array}{l}\text { Wall super- } \\
\text { heat }\end{array}$ & General & $\begin{array}{l}\text { Various, including } \\
\text { Russian/European }\end{array}$ & $\begin{array}{l}\text { Data is limited, often } \\
\text { conflicting, and raises } \\
\text { many questions. }\end{array}$ \\
\hline $\begin{array}{l}\text { Forced-flow } \\
\text { boiling }\end{array}$ & $\begin{array}{l}\text { Rankine } \\
\text { cycle working } \\
\text { fluid }\end{array}$ & General Electric & $\begin{array}{l}\text { Valid exploratory data; } \\
\text { good starting point for } \\
\text { follow-on tests. }\end{array}$ \\
\hline
\end{tabular}

In conclusion, it seems fair to say that past work in the two-phase alkalimetals field has raised more questions than it has provided answers. This situation was certainly not due to carelessness on the part of the experimenters but rather to the difficulties inherent in working with such fluids in twophase flow. Some time elapsed before these difficulties were fully recognized and only recently have steps been taken to account for all the variables affecting alkali-metal flow and heat transfer. It is highly recommended that future experiments pursue this approach to the limit. It will require elucidating and controlling all the major factors responsible for observed behavior. Ineluctably, consideration will have to be given to items that initially appear only distantly related to heat-transfer and flow concerns. These items may encompass characterization of the container/fluid interface, material compatibilities, contaminants, system history, and others, which are discussed in detail in the next section. Although past experiments have served to uncover--but not to explain--many mechanisms heretofore ignored in two-phase alkali-metal flow, future work must not only address all the issues which 
have been raised, but also must ascertain that no important issues are been overlooked. Only in this manner will reliable test data and meaningful correlations be ensured.

\subsection{PROPOSED TWO-PHASE ALKALI-METAL EXPERIMENTS (IN GRAVITY FIELDS)}

The broad intent of this experimental program is to obtain sufficient data to characterize two-phase alkali-metal flow and heat transfer in gravity fields (generally $1-\mathrm{g}$ ). While this goal is clear enough, its attainment is anything but straightforward, as has been intimated by previous sections here. The issues are manifold but can be grouped into several categories: materials, site(s), and test-loop and ancillary-equipment specifications. These will now be covered in turn.

\subsubsection{Approach}

First, the working fluid(s) must be selected. This selection is driven by the properties of the alkali metals--regarding both their effectiveness in heat transfer and their appropriateness to projected applications. A brief screening indicates that potassium, sodium, lithium, and possibly sodium/potassium alloy are the only viable choices among the liquid/alkali metals.

As for a site at which tests could be carried out, it is not clear which (if any) of the sites discussed previously is unequivocally superior to the others. Certain criteria must be met: previous experience with alkali metals is a must, as well as experience in dealing with exotic materials such as refractory alloys. But the overriding concern at any facility is the availability of state-of-the-art instruments and data acquisition systems. The latter will directly determine the quality and amount of the data. And the amount of data, given restricted budgets and complex tasks, is necessarily dependent on how well one can automate data acquisition and analysis, and control of the experiment itself. In the past, typical alkali-metal tests required the presence of up to $\sim 10$ technicians and engineers to control the tests and analyze the data. This is neither needful nor desirable today. 
The manpower complement can be reduced by $60 \%$ through use of state-of-theart equipment and techniques. In this context, probably none of the sites (except perhaps Aerojet) possesses the latest equipment, and all would require upgrading in this area. Thus, all facilities are equalized by possession of old equipment, which opens the choice to secondary concerns, such as distance of a test facility from the sponsoring organization.

The test loop design is a critical issue. Large loops are expensive to fabricate and house (especially if constructed of refractory alloy, which permits operation at higher temperatures than is possible with stainless steel or superalloys, but the refractories can operate only in a vacuum/nonoxidizing environment), and they require large amounts of well-regulated electrical power. So it probably would be best to initially construct small stainless steel loops for checkout tests. These loops would be relatively easy to construct and operate, and they would serve to clarify the need for large loops, more nearly representative of the space reactor designs.

The alternatives that have been presented offer no real engineering difficulties. In sum, 1) one would like to test several alkali metals to ensure universality of the correlations derived; 2) the choice of facility becomes one of convenience; 3 ) state-of-the-art test equipment must be specified; and 4) test loops can grow from small, relatively low-temperature devices to large, high-temperature ones, in a sort of evolutionary process, as the need arises. An approach of this type is readily adaptable to changing requirements.

\subsection{2 objectives}

Each experiment (e.g., pressure drop/flow regime, heat transfer, maximum heat flux) will consist of a series of tests whose objective is to "map" the parameters of interest over a broad range of conditions. The variables to be measured will consist of temperatures, pressures, mass-flow rates, velocities, and void fractions; flow regimes will be determined from film.

However, before these primary variables can be dealt with, some other issues must be delved into. As pointed out by Schultheiss (1973), the 
parameters influencing boiling can be segregated into two types:

thermohydraulic (i.e., the variables noted above) and physico-chemical. The latter encompasses the physical and chemical properties of all participating phases, especially at the liquid/solid interface. Included are considerations of container and wall surface roughness, corrosion, and wettability. Due to their chemical aggressiveness, alkali metal behavior is determined more by the physico-chemical parameters than is the case for water or organics. Kottowski (1973) had a similar list of important parameters and went on to analyze the mechanisms of nucleation by radiation, which may be significant in a nuclear reactor. In a more general analysis, he went on to investigate any physico-chemical property whose effect is to reduce the activation energy of a nucleus to values at which nucleation (i.e., bubble formation) becomes probable. The latest study (Kottowski and Savaterri, 1984) concludes that oxide impurities dominate nucleation processes.

Holtz, Fauske, and Eggen (1973) and Fauske (1973) suggest that the partial pressure of inert gas in surface cavities and system pressure-temperature history are dominant in affecting incipient boiling superheat (i.e., superheat at onset, either in time or of location, of boiling). A more recent experiment and data analysis led Zeigarnick and Litvinov (1980) to postulate that incipient boiling superheat is statistical in nature because no consistent trends were discovered in the data.

The above citations illustrate the complexity of the task. Some method must be found to uncover all potential parameters influencing boiling behavior of alkali metals. An objective manner of dealing with the parameters one by one must also be defined. Once the relative importance of the relevant parameters is established, the main ones will be controlled in the actual two-phase studies, which at this point become almost anticlimactic. That is, the process of acquiring the preliminary information required prior to doing the two-phase heat-transfer and pressure-drop experiments is probably more extensive than the main effort. But without a commitment to the preliminaries, it is doubtful that any reliable heat-transfer and pressure-drop correlations can be developed. 


\subsubsection{General Plans}

At this time, only preliminary conjectures regarding alkali-metal twophase experiments can be made. A more thorough literature review, especially of current European, Japanese, and Soviet work, is one of the first tasks. A critical review of the existing alkali-metal thermodynamic property data base is also a priority task. Numerous small experiments, with good statistical data analysis, are called for. These tasks can be accomplished relatively quickly and at low cost. Once these concerns have been satisfied, the twophase experiments sought to provide correlations can be designed and run.

\subsubsection{Conclusions and Recommendations}

A literature survey of alkali-metal two-phase flow reveals serious deficiencies in past experiments and data. The researchers themselves were usually cognizant of the aberrations in results and provided various explanations and suggestions to ameliorate the situation. Future experiments must build on this work and address the full complexity of mechanisms associated with alkali-metal flow and heat transfer. The plans for this task are somewhat more nebulous than is the case for the reduced-gravity experiments. Nevertheless, the general approach is the same: to study the issues in depth, and thereafter generate separate detailed documents for each experiment required. Here again, flexibility is an important consideration; as experiments are performed, the ability should be retained to modify succeeding experiments on the basis of the data obtained. 
.

. 


\subsection{SUMMARY AND CONCLUSIONS}

The two-phase alkali-metal correlations required by core thermal-hydraulic codes cannot be developed from existing data, even for normal gravity conditions. Reduced-gravity conditions confound the issues entirely. Thus, experiments must be scoped, planned, and carried out to provide sufficient, reliable data to permit development of correlations. The road to this goal is arduous and complex. No single all-encompassing experiment is feasible. Rather, experiments have been proposed that use various fluids, facilities, and experimental packages to supply the data. Arguments have been put forth supporting the view that a valid composite rendition of two-phase alkali-metal flow in a reduced-gravity environment will result from this partitioned approach. As experiments are performed, the approach initially taken may have to be modified (or even discarded) in order to fulfill the purpose of this task.

The recommended approach for MMW contractors is to quickly become involved in small-scale alkali-metal experiments in normal gravity. The best means for doing so is to fabricate new test loops using state-of-the-art instruments, at a convenient facility. A tentative work breakdown with a preliminary schedule is given in Figure 6.1 . 


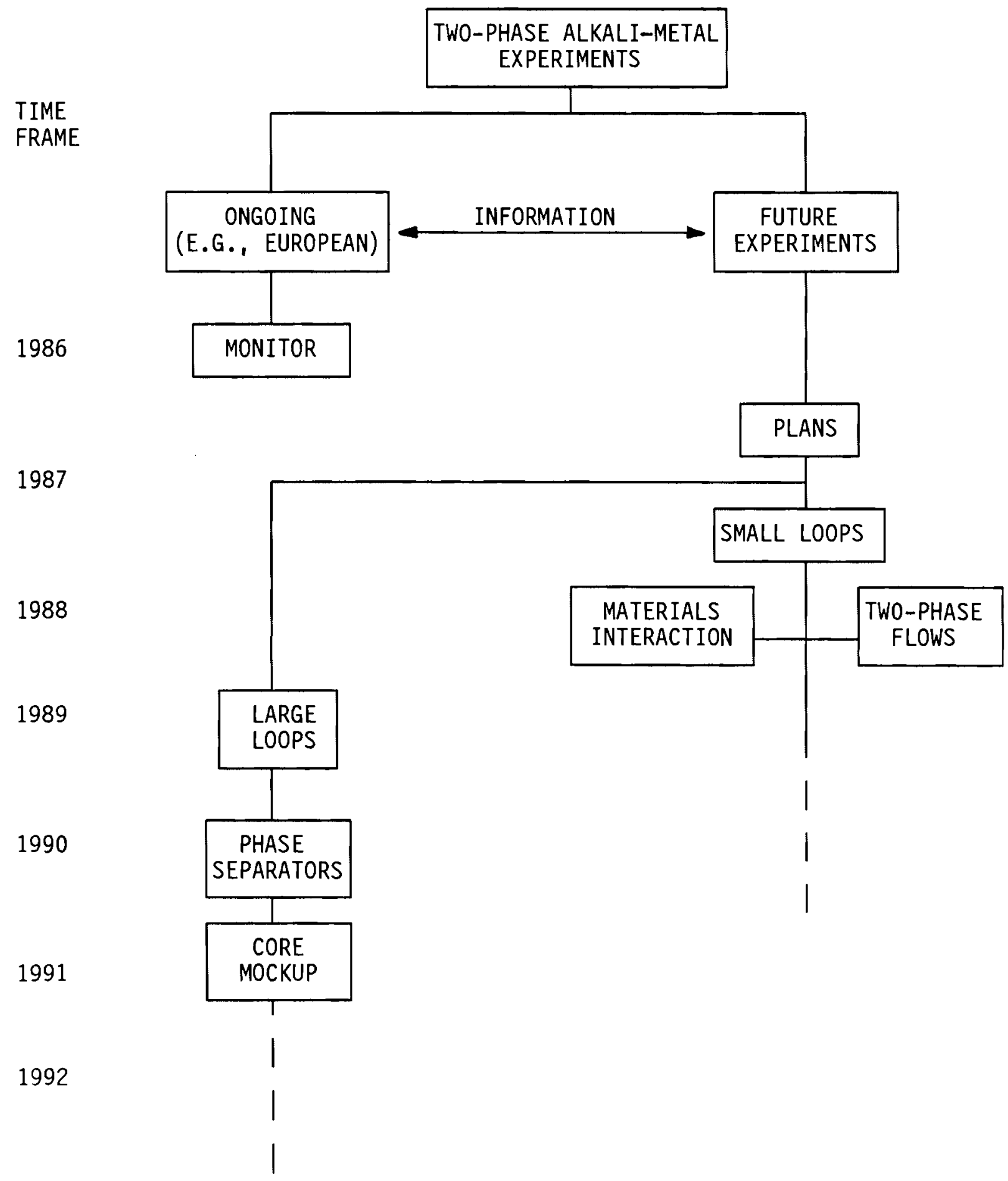

FIGURE 6.1. Two-Phase Alkali-Metal Experiment Task Flow 


\section{REFERENCES}

Albers, J. A. and R. P. Macosko. 1965. Experimental Pressure-Drop Investigation of Nonwetting, Condensing Flow of Mercury Vapor in a Constant-Diameter Tube in 1-G and Zero-Gravity Environments. National Aeronautical and Space Administration (NASA) TN D-2838.

Amos, J. C. 1975. Eacility Checkout and Design Point Demonstration. Vol. II of Advanced Rankine Cycle Potassium Boiler Development Program. NASA CR-135452.

Anderson, E. P. 1977. Electric Motors. 3rd ed. Theodore Audel, Indianapol is, Indiana.

Bomelburg, H. J. 1968. An Evaluation of the Applicability of Water Model Iesting to Liquid Metal Engineering Problems. Atomics International Liquid Metals Engineering Center, LMEC-68-4. Available from Clearinghouse for Federal Scientific and Technical Information, Springfield, Virginia.

Bomelburg, H. J. 1976. "Fluid Mechanics of Liquid Metals." In Vol. 2 of Sodium-NaK Engineering Handbooks, ed. 0. J. Faust, pp. 1-71. Gordon and Breach, New York.

Bradshaw, R. D. and C. D. King. 1977. Conceptual Design for Spacelab TwoPhase Flow Experiments. NASA CR-135327.

Chen, J. C. and S. Kalish. 1970. "An Experimental Investigation of Two-Phase Pressure Drop for Potassium with and without Net Vaporization." In Proceedings of 1970 International Heat Transfer Conference. Paper B8.3 in Vol. VI. Elsevier, Amsterdam, Holland.

Cochran, T. H. 1970. Forced-Convection Boiling Near Inception in Zero Gravity. NASA TN D-5612.

Cochran, T. H., J. C. Aydelott and C. M. Spuckler. 1967. An Experimental Investigation of Boiling in Normal and Zero Gravity. NASA TM X-52264.

Collier, J. G. 1972. Convective Boiling and Condensation. McGraw-Hill, New York.

Note: NASA documents are available from the National Technical Information Service (NTIS), Springfield, Virginia. 
Cooper, M. G., A. M. Judd, and R. A. Pike. 1978. "Shape and Departure of Single Bubbles Growing at a Wall." Paper presented at the Sixth International Heat Transfer Conference, August 7-11, 1978, Toronto, Canada.

Deane, C. W. 1975. Potassium Boiler and Condenser: Experimental Results. Vol. III of Advanced Rankine Cycle Potassium Boiler Development Program. NASA CR-135453.

Dwyer, 0. E. ed. 1973. Heat Transfer in Liquid Metals. Vol. 7 of Progress in Heat and Mass Transfer. Pergamon Press, New York.

Dwyer, 0. E. 1976. Boiling Liquid Metal Heat Transfer. American Nuclear Society, Hinsdale, Illinois.

Faber, 0. C. Jr. and Y. Y. Hsu. 1968. The Effect of a Vertical Magnetic Induction in the Nucleate Boiling of Mercury Over a Horizontal Surface. Vol. 64 of Chemical Engineering Progress Symposium Series, pp. 33-42. Am. Inst. Chem. Eng., New York.

Fauske, H. K. 1973. "Transient Liquid-Metal Boiling and Two-Phase Flow." In Heat Transfer in Liquid Metals, ed. 0. E. Dwyer, pp. 451-465. Vol. 7 of Progress in Heat and Mass Transfer. Pergamon Press, New York.

Fraas, A. P. 1964. "Boiling Potassium Reactor for Space." Nucleonics: 72-73.

Heppner, D. B., C. D. King, and J. W. Littles. 1975. "Zero-G Experiments in Two-Phase Fluids Flow Regimes." Paper presented at the Intersociety Conference on Environmental Systems, July 21-24, 1975, San Francisco, California.

Hetsroni, G., ed. 1982. Handbook of Multiphase Systems. Hemisphere Publishing, Washington, D.C.

Holtz, R. E., H. K. Fauske, and D. T. Eggen. 1973. "Incipient-Boiling Superheats for Sodium: Effects of History, Gas Content, and Approach to Boiling." In Heat Transfer in Liquid Metals, ed. 0. E. Dwyer, pp. 337343. Vol. 7 of Progress in Heat and Mass Transfer. Pergamon Press, New York.

Hsu, Y. Y. and R. W. Graham. 1976. Iransport Processes in Boiling and TwoPhase Systems. Hemisphere Publishing, Washington, D.C.

Jackson, C. B. et al. ed. 1955. Liquid Metals Handbook, Sodium (NaK) Supplement. 3rd ed. Atomic Energy Commission and Bureau of Ships, Department of the Navy, Washington, D.C.

Kays, W. M. 1966. Convective Heat and Mass Transfer, pp. 186-196. McGrawHill, New York. 
Keshock, E. G. et al. 1974. "A Photographic Study of Flow Condensation in 1-G and Zero-Gravity Environments." Paper presented at the Fifth International Heat Transfer Conference, September 3-7, 1974, Tokyo, Japan.

Kottowski, H. M. 1973. "The Mechanism of Nucleation, Superheating and Reducing Effects on the Activation Energy of Nucleation." In Heat Transfer in Liquid Metals, ed. 0. E. Dwyer, pp. 299-324. Vol. 7 of Progress in Heat and Mass Transfer. Pergamon Press, New York.

Kottowski, H. M. et a1. 1976. "Steady-State Liquid Metal Boiling Pressure Drop Characteristics". Paper presented at the International Conference on Fast Reactor Safety and Related Physics, October 5-8, 1976, Chicago, Illinois.

Kottowski, H. M. and C. Savatteri. 1984. "Fundamentals of Liquid Metal Boiling Thermohydraulics." In Nuclear Engineering and Design, ed. S. H. Fistedis. 82:281-304. North Holland Physics Publishing, Amsterdam, Holland.

Labus, T. L., J. C. Aydelott and R. F. Lacovic. 1972. Low-Gravity Venting of Refrigerant 11 . NASA TM X-2479.

MacPherson, R. E. Jr., and A. P. Fraas. 1965. "Potassium Rankine Cycle Operating Experience for the Medium Power Reactor Experiment." In Proceedings of the Specialists Conference on Rankine Space Power systems, Vol. II, pp. 11-34. NASA TID-22508.

Michelson, D. C. et al. 1983. Selected Publications Relevant to the Space Reactor Materials Program. Oak Ridge National Laboratory, Oak Ridge, Tennessee.

Murray, R. L. 1961. Introduction to Nuclear Engineering. 2nd ed. PrenticeHa11, Englewood Cliffs, New Jersey.

Namkoong, D. et a1. 1967. Photographic Study of Condensing Mercury Flow in 0 - and 1-G Environments. NASA TN D-4023.

NASA. No date. Microgravity Science and Applications, Brochure prepared by the Marshall Space Flight Center.

NASA. 1984. Spacelab 3. EP203.

NASA. 1985. In-Space Research, Technology, and Engineering Workshop. October 8-10, 1985, Williamsburg, Virginia.

Naumann, R. J. 1982. Microgravity Science and Application Program Description Document. NASA Marshall Space Flight Center (MSFC), Alabama. 
No, H. C. and M. S. Kazimi. 1982. "Wall Heat Transfer Coefficient for Condensation and Boiling in Forced Convection of Sodium." Nuclear Sci. and Eng. $81: 319-324$.

Oker, E. and H. Merte, Jr. 1973. Iransient Boiling Heat Transfer in Saturated Liquid Nitrogen and F113 at Standard and Zero Gravity. NASA CR-120202.

Pentecost, E. A. 1983. Materials Processing in Space. NASA TM-82525.

Pentecost, E. A. 1984. Microgravity Science and Applications Bibliography 1984 Revision. NASA TM-86651.

Petrash, D. A. and E. L. Corpas. 1973. "Zero Gravity Facility for Space Vehicle Fluid Systems Research." In Proc. 19th Annual Meeting of the Institute of Environmental Sciences. Inst. of Env. Sci., Mt. Prospect, Illinois.

Petukhov, B. S. and V. G. Zhilin. 1973. "Heat Transfer in Turbulent Flow of Liquid Metals in a Magnetic Field." In Heat Transfer in Liquid Metals, ed. 0. E. Dwyer, pp. 553-568. Vol. 7 of Progress in Heat and Mass Iransfer. Pergamon Press, New York.

Poppendiek, H. F. and C. M. Sabin. 1975. Technology of Forced Flow and OnceThrough Boiling. NASA SP-5102.

Salzman, J. A. 1985. "Two-Phase Fluid Management Technology Base." Paper presented at the NASA In-Space Research, Technology, and Engineering Workshop, October 8-10, 1985, Williamsburg, Virginia.

Schultheiss, G. F. 1973. "Aspects of Liquid-Metal Superheat and the Effects on Dynamic Boiling." In Heat Transfer in Liquid Metals, ed. 0. E. Dwyer, pp. 279-298. Vol. 7 of Progress in Heat and Mass Transfer. Pergamon Press, New York.

Schuster, J. R. 1985. "Liquid-Vapor Flow Regimes in Microgravity Experiments." Paper presented at the NASA In-Space Research, Technology, and Engineering Workshop, October 8-10, 1985, Williamsburg, Virginia.

Sears, F. W. and M. W. Zemansky. 1962. University Physics. 2nd ed. AddisonWesley, Reading, Massachusetts.

Shawhan, S. D. 1983. "A Spacelab Principal Investigator's Guidance for Planning Scientific Experiments Using the Shuttle." J. Spacecraft. $20(5): 477-483$.

Shelley, C. D. 1985. "Space Station Customer Utilization." Paper presented at the NASA In-Space Research, Technology, and Engineering Workshop, October 8-10, 1985, Williamsburg, Virginia. 
Shurney, R. E. ed. 1982. The Marshall Space Flight Center KC-135 Zero Gravity Iest Program for FY1981. NASA TM-82476, Huntsville, Alabama.

Siegel, R. 1967. "Effects of Reduced Gravity on Heat Transfer." In Advances in Heat Transfer, Vol. 4, pp. 143-228. Academic Press, New York.

Tong, L. S. 1965. Boiling Heat Transfer and Two-Phase Flow. Wiley, New York.

Wettach, R. H. Jr. ed. 1966. Einal Report, Rankine Cycle Test Facility Study. NASA CR-54972.

Wilcox, W. R. et al. 1981. A Preliminary Analysis of the Data from Experiment $77-13$ and Final Report on Glass Fining Experiments in Zero Gravity. NASA CR-161884.

Williams, J. L., E. G. Keshock and C. L. Wiggins. 1973. "Development of a Direct Condensing Radiator for Use in a Spacecraft Vapor Compression Refrigeration System." J. Eng. Ind.: 1053-1064.

Williams, J. L. 1974. Space Shuttle Orbiter Mechanical Refrigeration System. NASA CR-144395.

Yarosh, M. M. 1965. "Boiler Studies for the Medium Power Reactor Experiment." In Proceedings of the Specialist Conference on Rankine Space Power Systems, Vol. II, pp. 88-104, NASA TID-22508.

Zeigarnick, Yu. A. and V. D. Litvinov. 1980. "Heat Transfer and Pressure Drop in Sodium Boiling in Tubes." Nuclear Sci. and Eng. 73:19-28. 


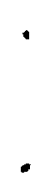

-

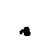


PNL-5906

UC -80

\section{DISTRIBUTION}

No. of

Copies

\section{QFFSITE}

David Wilson

Massachussetts Institute of Technology Department of Mechanical Engineering

Room 3-455

Cambridge, MA 02139

J. P. Nichols

Oak Ridge National Laboratory

MS 07

PO Box 4

Oak Ridge, TN 37831

Ward Enge 1

Oak Ridge National Laboratory

PO Box X

Oak Ridge, TN 37830

Peter Materna

Princeton University

P0 Box 451

Princeton, NJ 08544

R. W. Vernon

NASA Lewis Research Center

21000 Brookpark Road

Cleveland, $\mathrm{OH} 44135$

Charles Bell

Los Alamos National Laboratory

Los Alamos, NM 87545

William Sha

Argonne National Laboratory

9700 South Cass Avenue

Argonne, IL 60439
No. of

Copies

Hans Ludewig

Brookhaven National Laboratory

Upton, Long Island, NY 11973

Samit K. Bhattacharyya

Argonne National Laboratory

9700 South Cass Avenue

Argonne, IL 60439

Richard J. Bohl

Los Alamos National Laboratory

PO Box 1663

MS K560

Los Alamos, NM 87545

Roy H. Cooper

Oak Ridge National Laboratory

PO Box X

Oak Ridge, TN 37831

Louis 0. Cropp

Sandia National Laboratories

Box 5800

Albuquerque, NM 87185

Bruce B. Gillies

ETEC/Rockwe 11 International

PO Box 1449

Canoga Park, CA 91304

3 Ehsan U. Khan

Department of Energy

NE-521

Germantown, MD 20874 
Arthur T. Mattick

University of Washington

$\mathrm{FL}-10$

Seattle, WA 98195

Michael A. Merrigan

Los Alamos National Laboratory

PO Box 1663

Los Alamos, NM 87185

Nestor R. Ortiz

Sandia National Laboratories

Division 6430

PO Box 5800

Albuquerque, NM 87185

James R. Powell

Brookhaven National Laboratory

Upton, NY 11973

Richard E. Rice

EG\&G Idaho

PO Box 1625

Idaho Falls, ID 83415

Richard B. Rothrock

Los Alamos National Laboratory

Q-12

PO Box 1663-MS K551

Los Alamos, NM 87545

Gerhard Stapfer

Jet Propulsion Laboratory

4800 Oak Grove Drive

Pasadena, CA 91109

Earl J. Wahlquist

U.S. Department of Energy

Office of Nuclear Energy

washington, DC 20585
Carl E. Walter

Lawrence Livermore National Laboratory

Box 808-L-144

Livermore CA 94550

Herbert W. Hoffman

Oak Ridge National Laboratory

PO Box Y

Oak Ridge, TN 37831

Jack A. Salzman

NASA Lewis Research Center

21000 Brookpark Road

Cleveland, $\mathrm{OH} 44135$

Ronald J. Sovie

NASA Lewis Research Center

21000 Brookpark Road

Cleveland, $\mathrm{OH} \quad 44135$

Robert L. Wiley

OSD/SDIO

The Pentagon

Washington, DC 20301

Donald S. Rowe

14400 Bellevue-Redmond Road

Suite 208

Bellevue, WA 98007

Herman Merte, Jr.

University of Michigan

Department of Mechanical

Engineering and Applied

Mechanics

2250 G. G. Brown

Ann Arbor, MI 48109-2125

Abraham E. Dukler

University of Houston

Department of Chemical Engineering 4800 Calhoun

Houston, TX 77004 
Frederick R. Best

Nuclear Engineering Department

Texas A\&M University

College Station, TX 77843

30 DOE Technical Information Center
C. L. Wheeler

R. D. Widrig (5)

Publishing Coordination (2)

Technical Information (5)

\section{ONSITE}

3 Hanford Engineering Development Laboratory

D. S. Dutt

A. Padilla

W. L. Thorne

4 DOE Richland Operations Office
K. B. Absher (3)

J. J. Sutey

55 Pacific Northwest Laboratory

Z. I. Antoniak (10)

J. M. Bates

J. 0. Barner

D. B. Cearlock

T. T. Claudson

E. P. Coomes

J. M. Cuta

L. L. Eyler

M. A. Friesel

J. J. Holmes

B. J. Johnson

J. M. Kelly

W. J. Krotiuk (5)

N. J. Lombardo

D. R. Rector

L. C. Schmid

C. W. Stewart (5)

R. A. Stokes

D. S. Trent

B. J. Webb (5)

E. T. Weber 

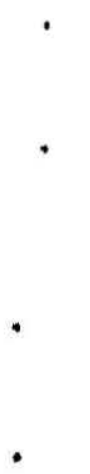